\title{
Organic corrosion inhibitors: where are we now? A review. Part I. Adsorption
}

\author{
Yu. I. Kuznetsov \\ A. N. Frumkin Institute of Physical Chemistry and Electrochemistry, Russian Academy \\ of Sciences, Leninskii pr. 31, Moscow, 119071 Russian Federation \\ E-mail: kuznetsov@ipc.rssi.ru
}

In memory of Professor Giordano Trabanelli

\begin{abstract}
A survey of studies on the adsorption of organic corrosion inhibitors (CIs) on metals from acid and neutral solutions for the period 2005-2015 is presented. It is noted that in order to estimate the adsorption of CI in corrosive acid solutions, the electrochemical impedance spectroscopy method (EIS) remains the most valuable. However, even the use of EIS for building CI adsorption isotherms is an approximation, which demands selecting the optimum conditions to reduce errors (control electrode potential, minimizing the rate of electrode dissolution, etc.). Besides, the conclusions about the state of the adsorption system and mechanism of adsorption of chemical substances can be made, at least, based on results of determining both the adsorption energy and the adsorption process kinetics. Addition of such a study to measure the aftereffect and XPS studies of the protective film formed on the metal by a CI provides valuable information about the nature of its adsorption.

In reviewing studies of CI adsorption in neutral aqueous solutions, much attention is paid to the in situ ellipsometry method. It is noted that the best conditions for such investigations may be produced on the surfaces of electrodes at potentials corresponding to the absence of intense cathodic hydrogen evolution or anodic dissolution of the metal. Examples of CI adsorption measurements by other in situ methods (EIS and electrochemical quartz microbalance, EQMB), the results of which are consistent with those of ellipsometry, are discussed. Results of successful application of ellipsometry in combination with the XPS studies of protective layers on various metals in the study of not only individual CIs but also mixtures thereof are provided. Ellipsometric studies have played an important role in the discovery of a new possibility of using CIs, which consists in successive formation of adsorption layers of different CIs on a metal (layer-by-layer coating).
\end{abstract}

Key words: metal corrosion inhibitors, adsorption, adsorption isotherm, electrochemical impedance, ellipsometry, X-ray photoelectron spectroscopy.

Received: September 17, 2015. Published: October 5, 2015.

doi: $10.17675 / 2305-6894-2015-4-4-1$ 


\section{Introduction}

An important task of physical chemistry and materials science is the development of effective methods of protection of metals (alloys) from corrosion in various corrosive media. One of these methods involves the use of corrosion inhibitors (CI), i.e., chemical compounds or formulations "which being present in the system in a sufficient concentration reduce the rate of metal corrosion without considerable changes in the concentration of any corrosive reagent" (Standard ISO 8044-1989). Prof. Trabanelli has made a huge contribution to this field of science, not only by his studies of organic CIs, but also by organizing at the University of Ferrara the unique symposia on CIs that lasted for half a century.

It is difficult within one lecture to discuss all the achievements in the science and practice of organic CIs made in recent years. In this regard, we consider briefly only the most fundamental aspects of the action of CIs, success in the study of which opens up new prospects for industrial application of CIs in anti-corrosion protection. It should be noted that the period covered by this paper begins in 2005 when the $10^{\text {th }}$ European Symposium on Corrosion and Scale Inhibitors took place.

Emphasis is given to three fundamental aspects: adsorption of CIs on a metal surface, its connection with the passivity of a metal (alloy) being protected, and dependence of CI efficiency on its chemical structure.

\section{Adsorption of CIs on the metal surface from acid solutions}

Adsorption on the surface to be protected is the first and often determining step that governs the efficiency of a CI. Difficulties of its measurement in situ are caused by the dissolution and/or oxidation of the metal substrate with time. Prof. G. Trabanelli in his Whitney Award Lecture (1991) [1] paid great attention to studies on the adsorption of CIs in acid solutions [1]. Although his group successfully used the method of labeled atoms for this purpose, unfortunately it must be acknowledged that over the past decade, this interesting though laborious method has not become widespread. For a long time, many researchers, including Prof. Trabanelli with co-authors, measured CI adsorption in acid solutions by electrochemical impedance spectroscopy (EIS) [2-10], often using a simple equivalent circuit of the electrode. They measured the decrease in the double layer capacitance $C_{\mathrm{dl}}$ attributed to the adsorption of the CI, which made it possible to build the adsorption isotherm and calculate the adsorption standard free energy $\left(-\Delta G_{\mathrm{A}}^{0}\right)$. Sometimes the degree of surface coverage by a $\mathrm{CI}(\theta)$ is calculated from the following equation:

$$
\theta=\eta(\%) 100=\left(R_{\mathrm{p}(i)}-R_{\mathrm{p}}\right) \cdot 100 / R_{\mathrm{p}},
$$

where $\eta$ is related inhibition efficiency, $R_{\mathrm{p}}$ is polarization resistance, which in the presence of CI is the sum $R_{\mathrm{ct}}+R_{\mathrm{a}}$. Here $R_{\mathrm{ct}}$ or $R_{\mathrm{ct}(i)}$ present the charge transfer resistance in the uninhibited and inhibited solution, respectively. $R_{\mathrm{a}}$ is the adsorption parameter, which is absent in uninhibited solution, i.e., in this case $R_{\mathrm{p}}=R_{\mathrm{ct}}$. 
Unfortunately, it can be often found in the literature that adsorption isotherms are derived from direct measurements of corrosion rates of a metal without taking into account the mechanism of CI action. Recently, the Editorial Board of our journal reminded about the need to be careful in these calculations which can lead to serious errors [11]. Here it should be added that, as a rule, acid corrosion of metals is an irreversible process. In this regard, even the use of EIS for building adsorption isotherms of a CI is an approximation, which demands selecting the optimum conditions to reduce errors (controlling the electrode potential, minimizing the rate of electrode dissolution, etc.).

Probably EIS is currently the most correct in situ method to study adsorption. In the past ten years, it was often used in combination with ex situ methods, primarily X-ray photoelectron spectroscopy (XPS) that can provide valuable information about the composition of ultrathin adsorption layers of CIs on metals [10, 12-16].

Our laboratory is also conducting such studies. They have led to the development of a CI having high efficiency not only in solutions of various acids but also in media containing hydrogen sulfide [17-24]. The main component of this inhibitor is a triazole derivative (IFKhAN-92) characterized by the ability to protect steel and other metals at elevated temperatures up to $200^{\circ} \mathrm{C}$.

The adsorption of IFKhAN-92 was studied with the use of EIS on a rotating disc electrode $(n=1000 \mathrm{rpm})$ made of mild steel (St3) with a working surface area of $0.64 \mathrm{~cm}^{2}$. Before experiments, the electrode was treated on grinding wheels with different grain sizes, polished with diamond paste, and degreased in acetone. In order to prevent surface dissolution of the steel electrode in the solution studied, the electrode was always cathodically polarized (at $E=-0.30 \mathrm{~V}$ with respect to the standard hydrogen electrode). A steel electrode was immersed in an acid solution and exposed until a constant capacitance was reached (for no more than $2 \mathrm{~h}$ ). Then, the needed inhibitor amount $\left(C_{\mathrm{in}}\right)$ was added to the solution and the electrode was again exposed until a constant capacitance was reached (up to $3 \mathrm{~h}$ ). Experiments were carried out in $2.0 \mathrm{M}$ acid solutions deaerated with argon at $t=22 \pm 1^{\circ} \mathrm{C}$. The solutions were prepared from chemically pure acid and double distilled water. The electrochemical impedance of the steel electrode was measured in a frequency range from $10 \mathrm{mHz}$ to $3 \mathrm{kHz}$ at an alternating voltage amplitude of $0.020 \mathrm{~V}$ with the use of an frequency response analyzer (FRA) connected to an IPCPRO FM potentiostat (developed in our Institute). The working and auxiliary platinum electrodes were mounted in a three electrode cell. A silver-chloride electrode was taken as the reference.

The coverage degree of the surface by the CI was estimated as follows:

$$
\Theta=\frac{C_{\mathrm{dl}}^{0}-C_{\mathrm{dl}}}{C_{\mathrm{dl}}^{0}-C_{\mathrm{dl}}^{\prime}},
$$

where $C_{\mathrm{dl}}^{0}, C_{\mathrm{dl}}$, and $C_{\mathrm{dl}}^{\prime}$ are the specific double layer capacitances of the steel electrode in the blank electrolyte, in solution containing the CI, and at the limiting adsorption of the CI on the metal, respectively. 
Although we have studied the adsorption of CIs of triazole class in solutions of various acids (e.g., $\mathrm{H}_{2} \mathrm{SO}_{4}, \mathrm{HCl}$ [22] and $\mathrm{H}_{3} \mathrm{PO}_{4}$ [24]), let us consider, as an example, the results obtained for $2.0 \mathrm{M} \mathrm{H}_{3} \mathrm{PO}_{4}$. It should be noted that these studies were carried out under stringent conditions: oxygen-free environment, cathodic polarization of steel that allow dissolution of the metal substrate to be minimized, and removal of released hydrogen gas using a rotating steel disk electrode. Compliance with these conditions allow us to hope that the measured pseudocapacity of the electrode is close to the true capacity of the double layer.

Measurements of the impedance of a steel electrode in a blank acid solution and in a solution containing IFKhAN-92 or its formulation with KCNS have shown that the Nyquist diagrams of the system are nearly perfect semicircles and an equivalent seriesparallel circuit should involve two resistors (here $R_{\mathrm{s}}$ is the solution resistance) and a capacitor (Figure 1). In an acid solution containing a CI, an increase in the steel electrode exposure leads to an increase in the hodograph radius, which indicates that $\mathrm{CI}$ adsorption is time dependent.

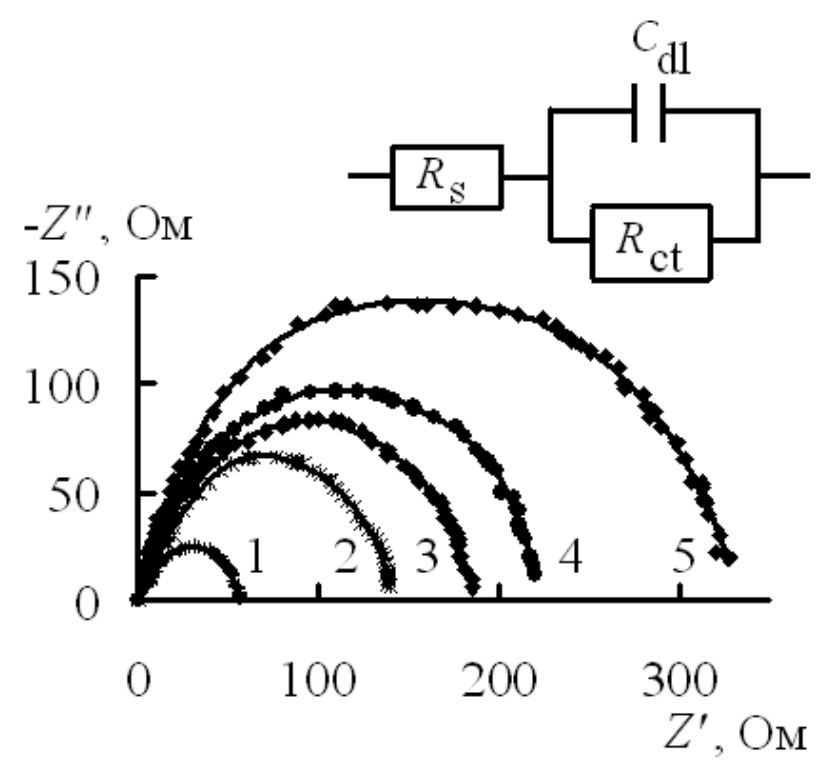

Figure 1. Equivalent electric circuit and Nyquist diagrams for a steel electrode recorded in $2.0 \mathrm{M} \mathrm{H}_{3} \mathrm{PO}_{4}$ without (1) and with $5.0 \mu \mathrm{M}$ IFKhAN-92 added $(2,3)$ or $5.0 \mu \mathrm{M}$ IFKhAN92 + $0.5 \mathrm{MM}$ KCNS added $(4,5)$ at exposures (in min): $30(2,4) ; 60(5 \mathrm{~s})$.

In the acid solution containing IFKhAN-92 or its formulation, an increase in exposure time of the steel electrode increases the hodograph radius, indicating that the process of CI adsorption proceeds in time. Under equal conditions $\left(C_{\text {IFKhAN-92 }}\right.$ and exposure time of the electrode in the solution), the radius of the Nyquist diagrams obtained on steel in an $\mathrm{H}_{3} \mathrm{PO}_{4}$ solution in the presence of the triazole is smaller than that in a solution containing $0.5 \mathrm{mM}$ KCNS.

The capacitance of a steel electrode in $2.0 \mathrm{M} \mathrm{H}_{3} \mathrm{PO}_{4}$ equals $40.8 \mu \mathrm{F} / \mathrm{cm}^{2}$. Upon adding IFKhAN-92 to the solution, the capacitance decreases for about $2 \mathrm{~h}$ and then remains 
nearly unchanged. With increasing concentration of the $\mathrm{CI}$ in the acid solution up to $C_{\text {in }}=$ $50 \mu \mathrm{M}$, the electrode capacitance decreases. At $C_{\text {in }}>50 \mu \mathrm{M}$, the decrease in capacitance stops, i.e., its value is extremely low $\left(14 \mu \mathrm{F} / \mathrm{cm}^{2}\right)$. Thus, the range of the limiting metal surface coverage with the $\mathrm{CI}$ is observed at $C_{\text {IFKhAN92 }} \geq 50 \mu \mathrm{M}$. In $\mathrm{H}_{3} \mathrm{PO}_{4}$ solution containing $0.5 \mathrm{mM} \mathrm{KCNS}$, the decrease in capacitance stops at $C_{\text {IFKhAN-92 }}=25 \mu \mathrm{M}$, and the capacitance of the electrode at these $C_{\mathrm{IFKhAN} 92}$ equals $14.2 \mu \mathrm{F} / \mathrm{cm}^{2}$.

Adsorption of IFKhAN-92 on steel surface (both in the absence and in the presence of KCNS) can be described by the Temkin isotherm:

$$
\Theta=1 / f \ln \left[B C_{\text {in }}\right],
$$

where $\Theta$ is the surface coverage by the CI, $f$ is the heterogeneity factor of the surface, and $B$ is the adsorption equilibrium constant (Figure 2). The calculated value of the $f$ parameter in the absence of KCNS is 7.31 and $B=1.7610^{7} 1 / \mathrm{mol}$. The presence of KCNS reduces the value $f$ to 6.29 , but increases $B$ to $2.38 \cdot 10^{7} 1 / \mathrm{mol}$. The $\left(-\Delta G_{\mathrm{A}}^{0}\right)$ value can be found from the following relationship:

$$
B=\frac{1}{55.5} \exp \left[\frac{-\Delta G_{\mathrm{A}}^{0}}{R T}\right]
$$

where $R$ is the universal gas constant and $T$ is the temperature in Kelvin scale. The values of $\left(-\Delta G_{\mathrm{A}}^{0}\right)$ for IFKhAN-92 calculated from Eq. (4) (both in the absence and in the presence of KCNS) within the reproducibility are equal to $51 \pm 1 \mathrm{~kJ} / \mathrm{mol}$. Thus, the presence of the KCNS additive in $\mathrm{H}_{3} \mathrm{PO}_{4}$ solution has no effect on the magnitude of $\left(-\Delta G_{\mathrm{A}}^{0}\right)$. The high value of $\left(-\Delta G_{\mathrm{A}}^{0}\right)$ allows us to assume that interaction between the $\mathrm{CI}$ and the metal surface is chemisorption. However, as it was correctly pointed out in [25], the conclusions about the state of the adsorption system and mechanism of adsorption of chemical substances can be made, at least, based on results of determining both the adsorption energy and kinetics of the adsorption process.

In order to characterize the kinetics of slow chemical adsorption of a substance on a heterogeneous surface, the Roginsky-Zeldovich equation is often used [4, 22, 25-27]. The adsorption kinetics of IFKhAN-92 on steel surface at relatively low CI concentrations is well approximated by a simplified Roginsky-Zeldovich equation:

$$
\Theta=\frac{1}{b} \ln \left[\frac{k}{b} \tau\right],
$$

where $\tau$ is time, and $b$ and $k$ are constants. The experimental $\Theta-\tau$ dependence can be linearized in a semilogarithmic scale (Figure 3), and the values of $b$ and $k$ constants at selected CI concentrations are listed in Table 1. The possibility to describe the adsorption kinetics of the CI by Eq. (5) is evidence in favor of the assumption of chemisorption IFKhAN-92 on steel surface, since exactly this process is described by this equation. 


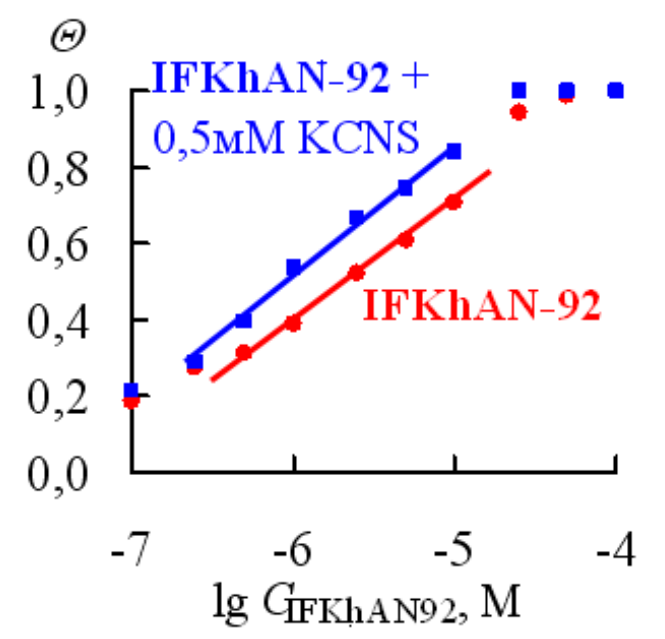

Figure 2. Adsorption isotherm for inhibitors (IFKhAN92 and IFKhAN92 + 0.5 mM KCNS) on mild steel $(E=-0.30 \mathrm{~V})$ in $2.0 \mathrm{M} \mathrm{H}_{3} \mathrm{PO}_{4}$ solution.

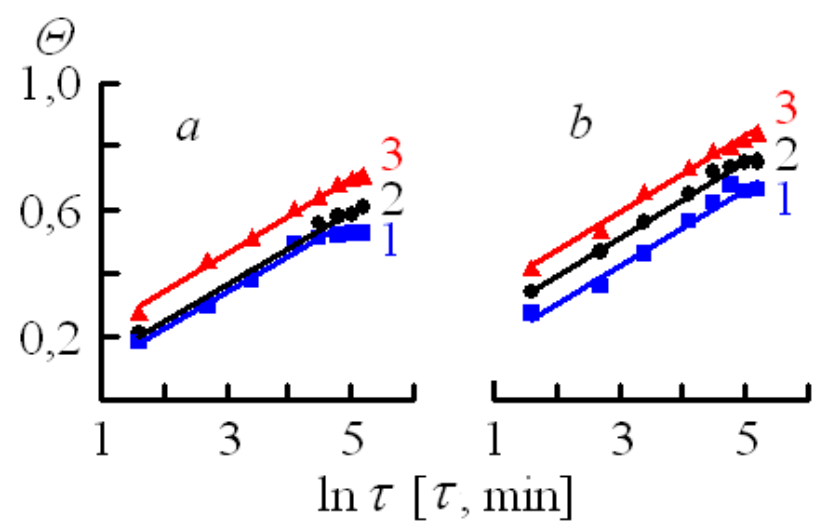

Figure 3. The coverage degree of mild steel surface $(E=-0.30 \mathrm{~V})$ versus the natural logarithm $\ln \tau$ depending on the time of adsorption in $2.0 \mathrm{M} \mathrm{H}_{3} \mathrm{PO}_{4}$ containing IFKhAN-92 (a) or its formulation with $0.5 \mathrm{mM} \mathrm{KCNS}(\mathrm{b})$ at IFKhAN-92 concentrations $(\mu \mathrm{M}): 1-2.5 ; 2-$ $5.0 ; 3-10$. Points are experimental data, and the lines were built by theoretical calculations using the Roginsky-Zeldovich equation.

Moreover, a study of the kinetics of IFKhAN-92 adsorption on steel has shown that the addition of KCNS significantly accelerates the adsorption of triazole. This is indicated by higher values of the $k$ constants in the Roginsky-Zeldovich equation observed for the $\mathrm{H}_{3} \mathrm{PO}_{4}$ solution containing KCNS. Probably this is one of the reasons explaining the high efficiency of the IFKhAN-92 formulation with KCNS in inhibition of steel corrosion in $\mathrm{H}_{3} \mathrm{PO}_{4}$ solutions compared to the individual triazole [28]. Apparently, the $\mathrm{CNS}^{-}$anions adsorbed on steel decrease the positive charge of the surface. As a result, it accelerates the adsorption of IFKhAN-92 that exists in the form of an organic cation. 
Table 1. Constants $k$ and $b$ in simplified form of the Roginsky-Zeldovich equation for CI adsorption on steel surface from $2.0 \mathrm{M} \mathrm{H}_{3} \mathrm{PO}_{4}$.

\begin{tabular}{cccc}
\hline $\boldsymbol{C}_{\text {IFKhAN-92, }} \boldsymbol{\mu M}$ & $\boldsymbol{C}_{\text {KCNS }}, \mathbf{m M}$ & $\boldsymbol{b}$ & $\boldsymbol{k}, \mathbf{~ m i n}^{-\mathbf{1}}$ \\
\hline 2.5 & 0 & 8.33 & 8.5 \\
5.0 & 0 & 8.33 & 8.8 \\
10 & 0 & 8.33 & 18.8 \\
2.5 & 0.5 & 8.33 & 13.3 \\
5.0 & 0.5 & 8.33 & 28.5 \\
10 & 0.5 & 8.33 & 54.4 \\
\hline
\end{tabular}

If our assumption regarding CI chemisorption on steel surface is correct, it is reasonable to expect that it would manifest a protective aftereffect (PAE). In order to clarify this assumption, steel specimens that had been exposed to an $\mathrm{H}_{3} \mathrm{PO}_{4}$ solution containing IFKhAN-92 were thoroughly washed in distilled water and immersed in a pure $\mathrm{H}_{3} \mathrm{PO}_{4}$ solution [21]. It turned out that, when immersed in the inhibitor-free solution, the specimens dissolve at rates close to those observed in the solution containing inhibitor. For example, preliminary adsorption of the $\mathrm{CI}$ on a specimen from $2.0 \mathrm{M} \mathrm{H}_{3} \mathrm{PO}_{4}$ solution containing $5.0 \mathrm{mM}$ IFKhAN-92 $+5.0 \mathrm{mM} \mathrm{KCNS}$ for $24 \mathrm{~h}$ at $25^{\circ} \mathrm{C}$ provides an $\mathrm{Z}$ value for the pure acid solution no smaller than $96.5 \%$ during $48 \mathrm{~h}$ (Table 2) [21].

Table 2. Corrosion rate $k\left(\mathrm{~g} /\left(\mathrm{m}^{2} \cdot \mathrm{h}\right)\right)$ and the coefficients of inhibition of steel corrosion $\gamma=k_{0} / k_{\text {in }}$ in $2,0 \mathrm{M}$ $\mathrm{H}_{3} \mathrm{PO}_{4}$, after preliminary exposure of specimen to the inhibitor-containing solution $\left(25^{\circ} \mathrm{C}, 24 \mathrm{~h}\right)$.

\begin{tabular}{|c|c|c|c|c|c|c|c|}
\hline \multirow{2}{*}{$\begin{array}{c}\text { Solution for preliminary CI } \\
\text { adsorption }\end{array}$} & \multirow{2}{*}{$k, \gamma$} & \multicolumn{6}{|c|}{$\begin{array}{l}\text { Exposure time of a steel specimen } \\
\text { in } 2.0 \mathrm{M} \mathrm{H}_{3} \mathrm{PO}_{4}, \mathrm{~h}\end{array}$} \\
\hline & & 1 & 4 & 10 & 24 & 48 & 72 \\
\hline- & $k$ & 11.4 & 7.32 & 4.70 & 2.84 & 2.30 & 2.86 \\
\hline \multirow{4}{*}{$\begin{array}{c}2.0 \mathrm{M} \mathrm{H}_{3} \mathrm{PO}_{4}+5.0 \mathrm{mM} \text { IFKhAN- } \\
92+5.0 \mathrm{mM} \mathrm{KCNS}\end{array}$} & $k$ & 0.20 & 0.14 & 0.12 & 0.08 & 0.08 & 0.35 \\
\hline & $\gamma$ & 57.0 & 52.3 & 39.2 & 35.5 & 28.8 & 8.2 \\
\hline & & \multicolumn{6}{|c|}{$C\left(\mathrm{H}_{3} \mathrm{PO}_{4}\right), \mathrm{M}$} \\
\hline & & 1.0 & & 4.0 & 6.0 & & 8.0 \\
\hline- & $k$ & 6.98 & & 9.0 & 10.6 & & 11.3 \\
\hline \multirow{2}{*}{$\begin{array}{c}2.0 \mathrm{M} \mathrm{H}_{3} \mathrm{PO}_{4}+5.0 \mathrm{mM} \text { IFKhAN- } \\
92+5.0 \mathrm{mM} \mathrm{KCNS}\end{array}$} & $k$ & 0.12 & & 0.80 & 0.91 & & 1.11 \\
\hline & $\gamma$ & 58.2 & & 11.3 & 11.6 & & 10.2 \\
\hline
\end{tabular}

The PAE of a CI layer formed on steel in the solution of $2.0 \mathrm{M} \mathrm{H}_{3} \mathrm{PO}_{4}+5.0 \mathrm{mM}$ IFHAN-92 $+5.0 \mathrm{mM} \mathrm{KCNS}\left(25^{\circ} \mathrm{C}\right)$ depends essentially on the duration of preliminary CI 
adsorption (Figure 4a). Only after $2 \mathrm{~h}$ of steel exposure to the inhibitor solution its layer is formed, providing $Z \geq 90 \%$. The PAE increases with an increase in the duration of the preliminary exposure of the specimen to the solution containing the CI. The best protective layer was formed on the second day, after which the quality somewhat deteriorated. It is of interest that KCNS itself has practically no protective action in $\mathrm{H}_{3} \mathrm{PO}_{4}$, and may even promote corrosion of steel [28]. However, in a binary mixture with IFKhAN-92, tiocyanide allows $C_{\text {IFKhAN-92 }}$ to be decreased to very low values (Figure $4 \mathrm{~b}$ ). The PAE of the CI layer formed on steel in $2.0 \mathrm{M} \mathrm{H}_{3} \mathrm{PO}_{4}+5.0 \mathrm{mM}$ IFKhAN-92 $+5.0 \mathrm{mM} \mathrm{KCNS}\left(25^{\circ} \mathrm{C}, 24 \mathrm{~h}\right)$ is observed in solutions of $\mathrm{H}_{3} \mathrm{PO}_{4}\left(25^{\circ} \mathrm{C}\right)$ in a wide range of its concentration, $C_{\mathrm{H} 3 \mathrm{PO} 4}$ (Table 2). A 8 -fold increase in $C_{\mathrm{H} 3 \mathrm{PO} 4}$ leads to a 9.3 -fold increase in the corrosion rate of steel, but at the same time the protection degree $Z$ remains above $90 \%$. It was shown in [21] that a PAE was observed in hot $\left(t \leq 80^{\circ} \mathrm{C}\right) 2 \mathrm{M} \mathrm{H}_{3} \mathrm{PO}_{4}$ solution $(2 \mathrm{~h})$ where corrosion rate of such samples was 37.1-176 times smaller than without preliminary $\mathrm{CI}$ adsorption.
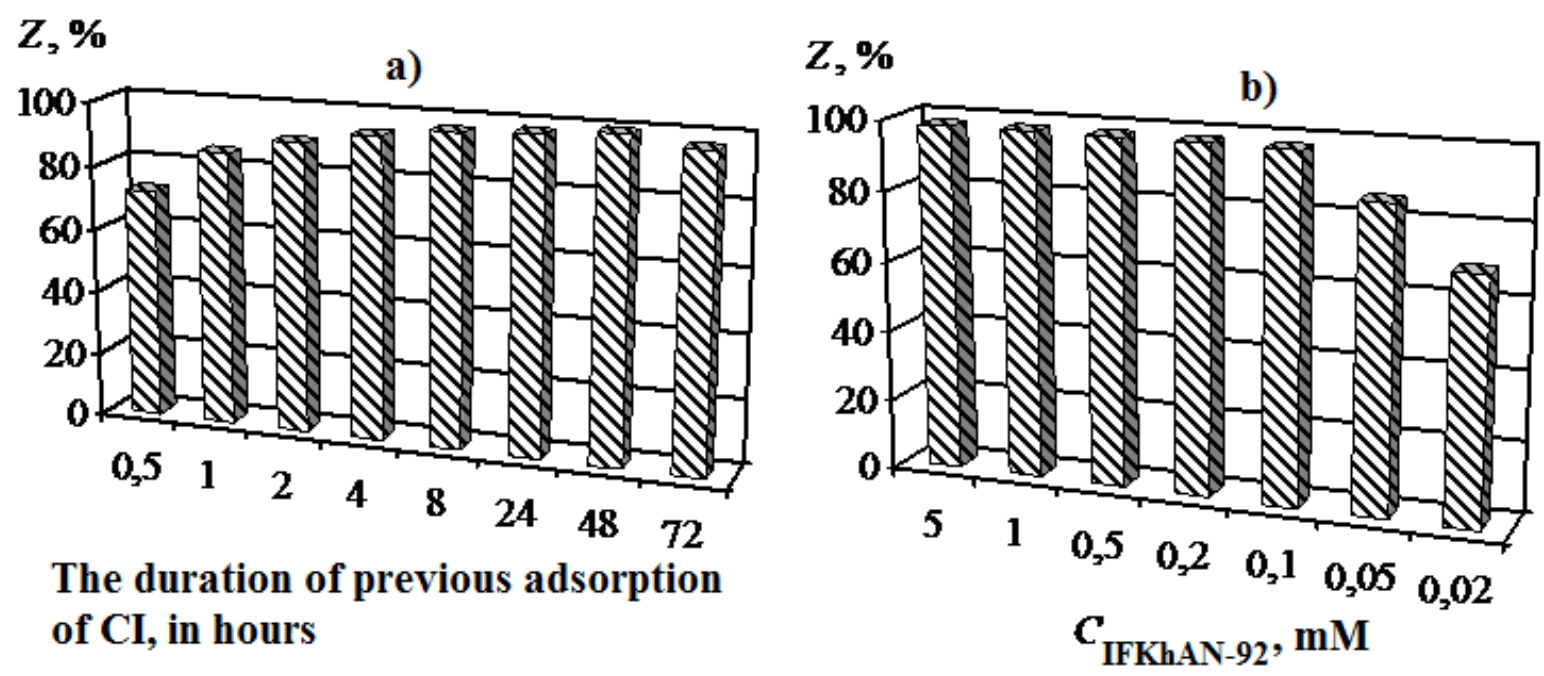

Figure 4. The degree of steel protection in a solution of $2 \mathrm{M} \mathrm{H}_{3} \mathrm{PO}_{4}$, after different exposure times in a solution of: $2 \mathrm{M} \mathrm{H}_{3} \mathrm{PO}_{4}+5 \mathrm{mM} \mathrm{KCNS}+5 \mathrm{mM}$ IFKhAN-92 (a) or $2 \mathrm{M} \mathrm{H}_{3} \mathrm{PO}_{4}+$ $5 \mathrm{mM} \mathrm{KCNS}+\mathrm{x} \mathrm{mM} \mathrm{IFKhAN}-92(\mathrm{~b})$. The exposure time is 2 hours; $t=25^{\circ} \mathrm{C}$.

The high PAE values of layers formed on steel in $\mathrm{H}_{3} \mathrm{PO}_{4}$ solutions containing the IFKhAN-92 + KCNS mixture suggest the chemisorption nature of the interaction between the surface metal atoms and the CI. Valuable information on the composition and structure of these layers was obtained by XPS analysis [21].

Due to the complexity of the $\mathrm{Fe} 2 \mathrm{p}$ doublet and satellite peaks observed at high binding energies $\left(E_{\mathrm{b}}=705-740 \mathrm{eV}\right)$, it was assumed that there is a layer consisting of $\mathrm{Fe}_{3} \mathrm{O}_{4}$ and $\mathrm{FeOOH}$ on steel surface. The presence of oxygen of different types follows from the O1s spectrum (Figure 5), which can be resolved into three peaks corresponding to water molecules $\left(E_{\mathrm{b}}=533.5 \mathrm{eV}\right)$, hydroxyl groups $(531.8 \mathrm{eV})$, and oxygen within the oxide lattice $(530.3 \mathrm{eV})$. Despite thorough washing of the samples, the complex XP 
spectrum of the N1s electrons indicates the presence of a CI film on a steel surface kept for $24 \mathrm{~h}$ in $2.0 \mathrm{M} \mathrm{H}_{3} \mathrm{PO}_{4}+5.0 \mathrm{mM}$ IFKhAN-92 $+5.0 \mathrm{mM} \mathrm{KCNS}$. The observed spectrum can be decomposed into two peaks (401.4 and $399.5 \mathrm{eV}$ ) with a ratio of about 1:3-3.4, where the second peak should be attributed to the nitrogen atoms of the triazole group. This peak, in the case where the electron S2p peak due to sulfur is also observed, will include the contribution of the nitrogen atoms of CNS group, whose peak position practically coincides with the peak position of the nitrogen atoms of the triazole ring.

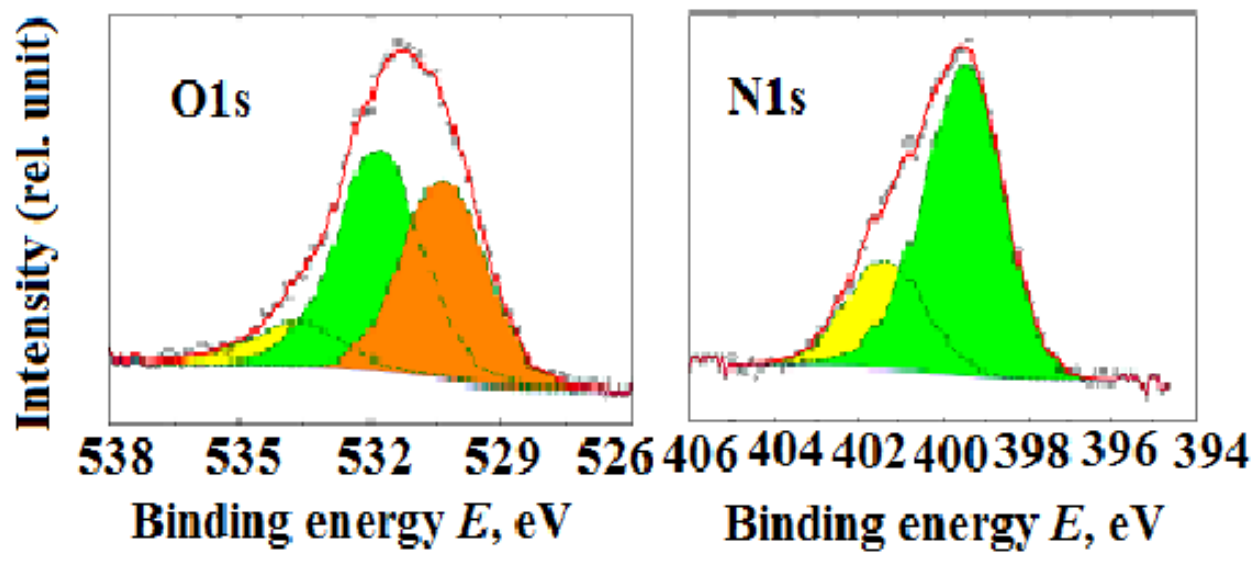

Figure 5.XPS spectra $\mathrm{O} 1 \mathrm{~s}$ and $\mathrm{N} 1 \mathrm{~s}$ electron of steel surface after preliminary adsorption of a CI (5.0 mM IFKhAN-92 + 5.0 mM KCNS) from $2.0 \mathrm{M} \mathrm{H}_{3} \mathrm{PO}_{4}$ at $25^{\circ} \mathrm{C}$ for $24 \mathrm{~h}$.

Based on the quantitative ratios of atoms derived from the integral intensities of X-ray photoelectron spectra, it was concluded [21] that a polymolecular layer consisting of a CI (IFKhAN-92), $\mathrm{Fe}$ (II) cations and thiocyanate anions with a thickness above $4 \mathrm{~nm}$ formed on steel surface in $24 \mathrm{~h}$. After washing the steel surface 3 times with distillated water in an ultrasonic bath, the surface layer with a thickness of $3 \pm 0.5 \mathrm{~nm}$ remains on the steel, that corresponds to 3-4 layers of a complex compound (Figure 6). It is suggested that it consists of 1 molecule of CI (IFKhAN-92), 0.5 Fe (II), 0,5 NCS ${ }^{-}$and it should be closed to the structure of the complex $\mathrm{Fe}$ (triazole $)_{4}(\mathrm{CNS})_{2}$. It is chemisorbed layer on the steel substrate partially coated with oxides and hydroxides of iron. ${ }^{1}$

Thus, the data of XPS analysis confirmed the chemisorption character of interaction of the CI (IFKhAN-92 + KCNS) with steel surface in $2.0 \mathrm{M} \mathrm{H}_{3} \mathrm{PO}_{4}$ solution. The binding energy of IFKhAN-92 molecules with the steel surface is sufficiently high so that they are not removed from the steel surface during ultrasonic cleaning and XPS studies. It is of interest that ultrasonic cleaning only slightly removes the upper layers of the protective film to leave a layer $3 \pm 0.5 \mathrm{~nm}$ thick that preserves the PAE to a considerable extent. Another indirect confirmation of CI chemisorption on steel surface is the fact that increasing the temperature of the solution for pre-adsorption of IFKhAN-92 + KCNS from $20^{\circ}$ to $60^{\circ} \mathrm{C}$ increases the PAE in $2.0 \mathrm{M} \mathrm{H}_{3} \mathrm{PO}_{4}$ [21].

\footnotetext{
${ }^{1}$ A more detailed explanation of the suggested scheme of the protective layer is given in our paper [21].
} 


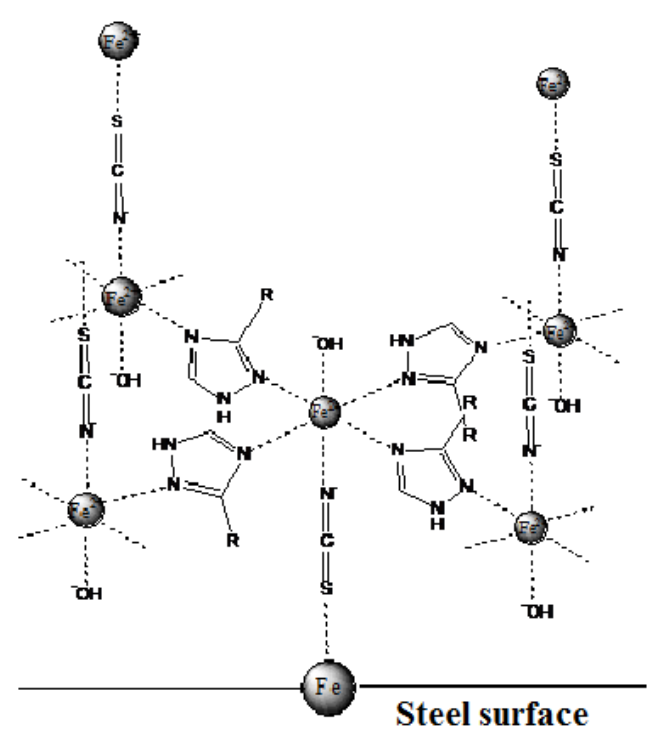

Figure 6. Scheme of the structure of the protective layer formed on steel after CI adsorption from a solution containing 2.0 $\mathrm{M} \mathrm{H}_{3} \mathrm{PO}_{4}, 5.0 \mathrm{mM}$ IFKhAN-92, and 5.0 $\mathrm{mM} \mathrm{KCNS}\left(25^{\circ} \mathrm{C}, 24 \mathrm{~h}\right)$.

Thus, in a $\mathrm{H}_{3} \mathrm{PO}_{4}$ solution containing a IFKhAN-92 + KCNS formulation, a polymolecular protective layer (up to $4 \mathrm{~nm}$ ) is formed on steel. Its lower layer is chemically bound to the surface atoms of iron through "thiocyanate" bridges. Each overlying layer of $\mathrm{CI}$ also chemically interacts with the adjacent layers through thiocyanate anions. Inside the monolayer, IFKhAN-92 molecules are linked through bridging $\mathrm{Fe}(\mathrm{II})$ cations. Such a polymolecular layer provides a high PAE in $\mathrm{H}_{3} \mathrm{PO}_{4}$ solutions. The PAE of the protective film formed by IFKhAN-92 is preserved to large extent even after removal of upper layers by ultrasonic cleaning.

In the above example of inhibition of acid corrosion of steel one can see the potential of modern methods of research in studies on the mechanism of CI action and the development of methods to increase CI efficiency. However, it should be pointed out that studies of adsorption of organic CIs at elevated temperatures $\left(\geq 80^{\circ} \mathrm{C}\right)$ are almost completely missing. The reason is that these studies involve considerable methodological difficulties, although nowadays the practice of metal protection has dictated the need for developing high temperature CIs, and, hence, studying the mechanism of their action, primarily adsorption of CIs on the metal being protected.

\section{Adsorption of organic CIs on metals from neutral aqueous solutions}

Intense studies of $\mathrm{CI}$ adsorption on metals from neutral aqueous solutions began in the mid-1980s. Bockris et al. $[29,30]$ used a radiometric method to show that in a borate buffer with $\mathrm{pH} 8.4$ the adsorption of thiourea and thiocyanate on oxidized iron (50 min at $E=0.3 \mathrm{~V}$ ) occurs over a wide range of potentials with displacement of water molecules (the Bockris-Swinkels isotherm). At the same time, we have shown that ellipsometry combined with electrochemical measurements is a powerful in situ method that may be 
useful in studying the adsorption of anions of organic acids on iron electrode surface in borate buffer with $\mathrm{pH} 7.4$ [31]. Ellipsometry can be used to study the adsorption of organic compounds on the electrode surface only provided that ellipsometric angles $\Delta$ and $\Psi$ at a given electrode potential in the initial solution do not change with time. Only in this case, variation in the $\Delta$ and $\Psi$ values upon addition of an organic compound concentrate into the electrochemical cell can serve as a measure of its adsorption on the electrode. That is why the best conditions for such investigations may be produced on the surfaces of electrodes at potentials corresponding to the absence of intense cathodic evolution of hydrogen or anodic dissolution of the metal $[31,32]$. The variation of ellipsometric angle $\left(\delta \Delta=\Delta-\Delta_{0}\right.$, where $\Delta_{0}$ corresponds to the surface before addition of the adsorbate being studied) as a function of the adsorbate concentration $\left(C_{\text {in }}\right)$ can be used to determine the type of the adsorption isotherm, and its equation can be used to calculate the adsorption constants. In the case of an oxidized electrode, one must assume that variation of the electron concentration in the surface layer due to adsorption does not noticeably affect the $\Delta$ value. This statement was based on the results [33] where it was shown for a three-layer system on iron surface (outer layer of adsorbed organic molecules - electron-enriched or depleted thin oxide layer - phase oxide) that variations in the phase shift angle $\delta \Delta$ due to a twofold increase or decrease in the electron concentration are low $\left(<0.1^{\circ}\right)$. As the $\delta \Delta$ values in the case of measurements of organic compound adsorption are generally many times higher (sometimes, by orders of magnitude), they were related in our papers solely to the variation in the amount of the adsorbed compound or ion.

Even in our earliest work [31,34] where we studied the adsorption of sodium phenylanthranilate, $\mathrm{NaOOCC}_{6} \mathrm{H}_{4} \mathrm{NHC}_{6} \mathrm{H}_{5}$ ( $\mathrm{SPhA}$ ) from borate buffer with $\mathrm{pH} 7.4$, the features of $\mathrm{CI}$ interaction with a reduced and oxidized surface of pure Fe were identified. The ellipsometric isotherms are in agreement with the results of EIS studies of adsorption. The parameters of isotherms obtained by two independent methods for SPhA adsorption on iron electrode were similar [34]. Despite the low magnitude of $\left(-\Delta G_{\mathrm{A}}^{0}\right)<20 \mathrm{~kJ} / \mathrm{mol}$, it has been proved that its adsorption can be partially irreversible and can passivate the metal even in the absence of iron oxides.

Recently [35] we used another independent in situ method to estimate SPhA adsorption on a metal electrode from borate buffer solution with $\mathrm{pH}$ 7.4. The electrochemical quartz microbalance (EQMB) method is based on the changes in the piezo-quartz resonator frequency upon variation of the mass of the substance applied (adsorbed) on its surface according to the Sauerbrey equation [36]:

$$
\Delta m=-\left(N \rho S \Delta f / f_{0}^{2}\right)=\Delta f / K,
$$

where $f_{0}$ is the basic frequency, $\mathrm{kHz} ; \Delta m$ is the variation in the mass applied to the piezoquartz resonator, $\mathrm{g} ; N$ is the frequency constant (in the case of AT-cut crystals, $N=1670$ $\mathrm{kHz} \mathrm{mm}$ ); $\rho$ is the density of quartz, i.e., $2.65 \mathrm{~g} / \mathrm{cm}^{3} ; S$ is the quartz working area equal to $0.72 \mathrm{~cm}^{2}$. In this equation, $K$ is the sensitivity coefficient of the quartz nanobalance that includes all the constants defined by the physical parameters of quartz. 
With regard to technical metals (such as iron, copper, and others) in aqueous solutions, this method is generally used to study the kinetics of corrosion, including that in the presence of a CI. Copper corrosion inhibition is the system that is studied most often [3742]. G. Trabanelli et al. [37], who studied the corrosion inhibition of copper by various heterocyclic compounds (BTA, 2,4-dimercapto-pyrimidine, 5-mercapto-1-phenyltetrazole, $1 H-1,2,3$-triazolo[4,5-b]pyridine) in $0.1 \mathrm{M} \mathrm{NaCl}$ concluded that "EQCM technique has a valuable part to play in the interpretation of corrosion and corrosion inhibition mechanisms". However, they also noted that $\Delta m$ values resulted from a sum of different processes: adsorption of $\mathrm{CI}$ and formation of surface film, formation of solid surface compounds and dissolution of soluble compounds. Hence, it is very difficult to distinguish these effects. It is probably the reason that adsorption of organic compounds from aqueous solutions is studied on noble metals $(\mathrm{Au}, \mathrm{Pt})$ [44-48] that exhibit high corrosion resistance in the initial solution. In order to compare the adsorption properties of SPhA we carried out measurements by ellipsometry and EQMB on gold electrode in borate buffer [35].

In order to stabilize the state of the spray gold electrode surface, its pretreatment was performed by switching the potential from $E=1.8 \mathrm{~V} \mathrm{NHE}$ and conditioning for $15 \mathrm{~s}$ to $E=$ $-0.2 \mathrm{~V}$ and conditioning for $0.2 \mathrm{~s}(3-4$ times) followed by switching off the potential until the free corrosion potential $E_{\text {cor }}=0.34 \mathrm{~V}$ was established [48]. Adsorption was measured at $E=0.32 \mathrm{~V}$, i.e., in the range of potentials where neither gold oxidation nor reduction occurs. Then a certain amount of $0.25 \mathrm{M} \mathrm{SPhA}$ solution in borate buffer solution was gradually introduced into the cell and the mass variation was recorded. Each subsequent portion of the additive was introduced after the mass variation was not more than $1 \mathrm{ng}$ per $10 \mathrm{~min}$, i.e. it stabilized. The $\mathrm{SPhA}$ concentration in the cell was calculated and the dependence of the adsorbed substance mass on time was plotted.

In ellipsometric studies, the a gold foil was used as the electrode. It was polished on a fine abrasive paper and finished on felt impregnated with an aluminum oxide suspension. Before introduction into the electrochemical cell, the electrode surface was degreased with ethanol, rinsed with twice distilled water and borate buffer solution. The SPA concentrate was added portionwise after constant values of $\Delta$ and $\Psi$ angles were established. Cyclic surface treatment of the gold electrode was performed 3-4 times with subsequent switching off the potential until $E_{\text {cor }}=0.28 \mathrm{~V}$ was established. The measurements were performed at $E=0.26 \mathrm{~V}$.

As illustrated in Figure 7, the time of mass stabilization of the quartz resonator for various $C_{\mathrm{SPhA}}$ values is usually $0.5-1 \mathrm{~h}$. An increase in the electrode mass with an increase in $C_{\mathrm{SPhA}}$ from 0.49 to $0.96 \mathrm{mM}$ allows the assumption to be made that surface coverage $\theta$ is close to 1.0. The adsorption isotherm was built from these mass variation data (Figure 8). It was also shown that rather a long time is required for equilibrium establishment after introduction of SPhA in ellipsometric measurements, as compared to the quartz resonator mass variation. After building the experimental dependence of $\delta \Delta=\Delta-\Delta_{0}$ on the SPhA concentration, the $\Delta_{0}$ angle corresponds to the maximum angle value at each concentration. The SPhA adsorption isotherm obtained using the ellipsometric method is presented in 
Figure 8 . The main assumptions in the interpretation of ellipsometric measurements are as follows: the film homogeneity across thickness; proportionality between the film thickness and the variation in angle $\Delta$; coverage $\theta$ is 1 when angle $\Delta$ stops varying upon increasing the adsorbed substance concentration, i.e., it reaches a plateau on the curve of the $\delta \Delta$ versus $\log C$.

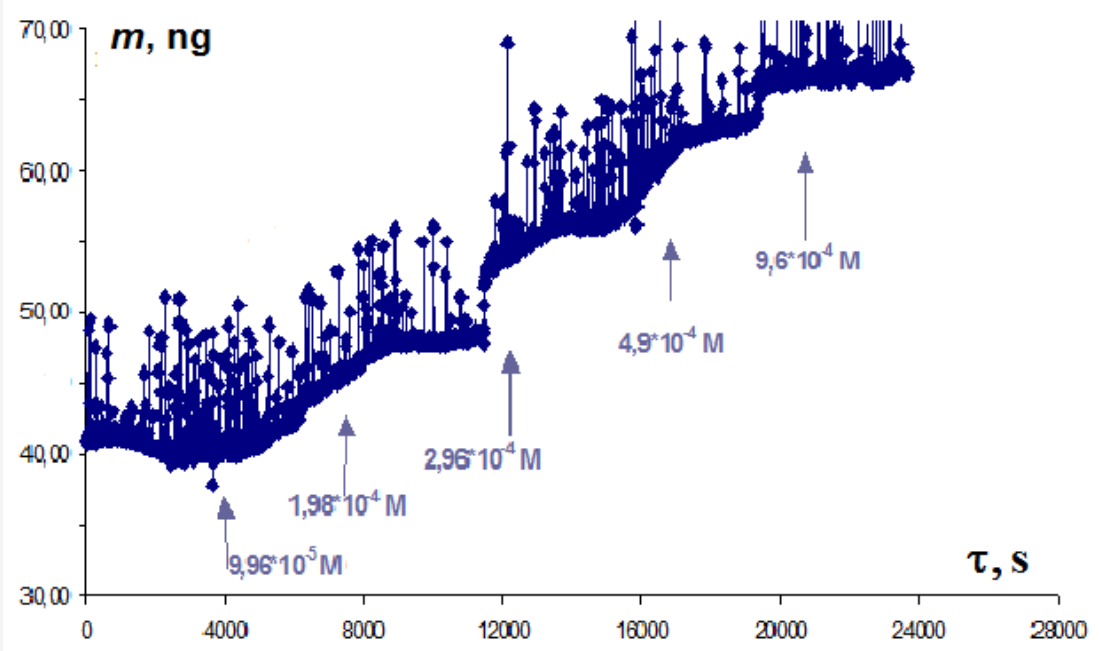

Figure 7. Mass variation of the substance adsorbed on a gold electrode, $\mathrm{SPhA}$, versus time for various $\mathrm{SPhA}$ concentrations in borate buffer solution with $\mathrm{pH} 7.4$ at $E=0.32 \mathrm{~V}$.

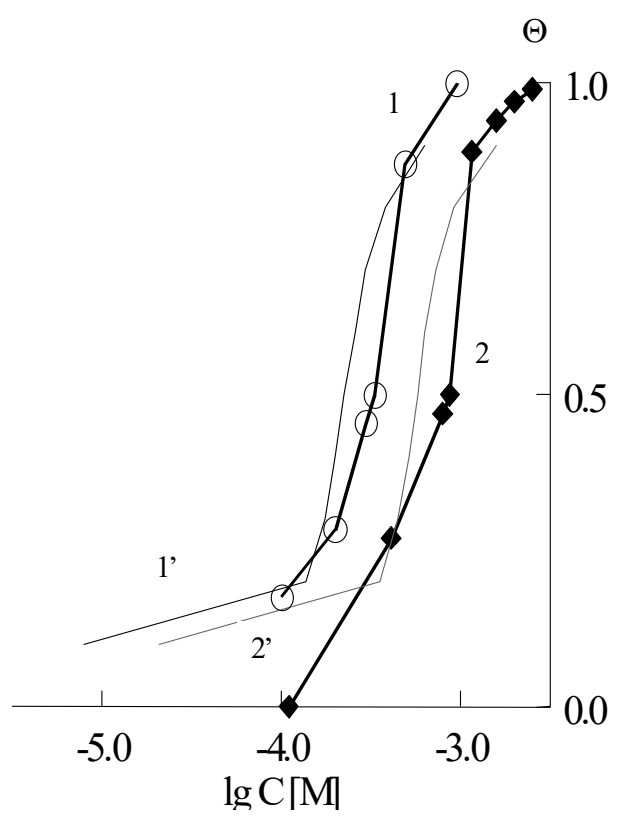

Figure 8. SPhA adsorption isotherms on a gold electrode obtained using the following methods: (1) piezo-quartz nanobalance, (2) ellipsometry; $\left(1^{\prime}\right)$ and $\left(2^{\prime}\right)$ are the theoretical curves. 
As follows from consideration of these data, isotherms of the SPhA anion adsorption from borate buffer solution on a gold electrode surface at similar potentials obtained using the piezo-quartz nanobalance and ellipsometry methods are in the same concentration range and are outwardly similar. In terms of statistical hypotheses, the SPhA adsorption isotherm obtained using the two methods is assumed to obey the Frumkin equation at 95\% level:

$$
B c=[\theta /(1-\theta)] \cdot \exp (-2 a \theta),
$$

where $a$ is the attraction constant characterizing the interaction between the adsorbate particles and $B$ is the adsorption equilibrium constant. Ellipsometry gave the following values: $\left(-\Delta G_{\mathrm{A}}^{0}\right)=24.17$ and $a=1.48 \pm 0.3$; the EQMB method gave quite similar values: $26.7 \mathrm{~kJ} / \mathrm{mol}$ and $1.45 \pm 0.5$, respectively. $F$-test analysis indicates that the $\mathrm{SPhA}$ isotherms obtained using the two methods are statistically indistinguishable to within $95 \%$. The small difference in the adsorption energy values obtained using different methods was explained by the fact that the electrode potentials are though close but still differ and by different properties of the adsorbing surfaces (spray gold and gold foil).

Thus, the results of [35], in particular the proximity of the parameters of SPhA adsorption isotherms measured by two independent in situ methods, as well as earlier results reported in [34], evidence in favor of the correctness of the assumptions made by us during the ellipsometric studies. It is not surprising that over the last decade we have expanded the range of CIs whose adsorption was studied on verions metals and alloys.

Even in our work [49] we have expanded the objects of CI adsorption study on zonemelted iron by examining the behavior of not only SPhA but also of sodium salts of acids: mephenamic, $o$-[2,3( $\left.\left.\mathrm{CH}_{3}\right)_{2} \mathrm{C}_{6} \mathrm{H}_{5} \mathrm{NH}\right] \mathrm{C}_{6} \mathrm{H}_{4} \mathrm{COONa}(\mathrm{SMePh})$; N-(3-difluormethyltiophenyl)anthranilic, $o$-[3-( $\left.\left.\mathrm{SCHF}_{2}\right) \mathrm{C}_{6} \mathrm{H}_{4} \mathrm{NH}\right] \mathrm{C}_{6} \mathrm{H}_{4} \mathrm{COONa}, \quad(\mathrm{SDF}) ; \quad$ fluphenamic $o$-[3$\left.\left(\mathrm{CF}_{3}\right) \mathrm{C}_{6} \mathrm{H}_{4} \mathrm{NH}\right] \mathrm{C}_{6} \mathrm{H}_{4} \mathrm{COONa}$, (SFPh). As shown previously [50], these substituted SPhAs are more efficient CIs in neutral solutions not only for iron or low carbon steel, but also for other metals ( $\mathrm{Al}$ and its alloys, $\mathrm{Zn}$ ). Therefore, it is not surprising that they are better adsorbed on reduced $(E=-0.65 \mathrm{~V})$ and oxidized iron $(E=0.2 \mathrm{~V})$ than $\mathrm{SPhA}$, although their adsorption, like that of SPhA, is also limited to formation of a monolayer. As can be seen from adsorption constants and the $\left(-\Delta G_{\mathrm{A}}^{0}\right)$ values presented in Table 3 , anions of the $\mathrm{SPhA}$ derivatives, in particular, $\mathrm{SFPh}$ and $\mathrm{SDF}$, are strongly adsorbed not only at positively charged passive iron surface (at $E=0.2 \mathrm{~V}$ ) but also at much less positive potentials where the electrode surface is not oxidized $(E=-0.65 \mathrm{~V})$.

The results of adsorption studies of the CIs agree well with the results of our polarization measurements and corrosion tests. It is noteworthy that the SPhA derivatives are adsorbed more easily on oxide-free iron surface than on the oxide grown under anodic polarization (for SDF, the adsorption energies are very close to each other). Obviously, the electrostatic component of the adsorption energy, which is determined by the interaction of the charged surface and the anion, differs in the two cases. Unfortunately, the surface charge cannot be determined because of the lack of precise data on the zero-charge potential of oxidized iron and the potential drop built in to the oxide at $E=0.2 \mathrm{~V}$. 
Table 3. Adsorption constants and free adsorption energies of $\mathrm{SPhA}, \mathrm{SFPh}, \mathrm{SMePh}$ and $\mathrm{SDF}$ for their adsorption on reduced $(E=-0.65 \mathrm{~V})$ and oxidized iron surface $(E=0.2 \mathrm{~V})$ from borate buffer solution (pH 7.36).

\begin{tabular}{ccc}
\hline Compound & $\boldsymbol{E}=\mathbf{- 0 . 6 5 ~ V}$ & $\boldsymbol{E}=\mathbf{0 . 2 0} \mathrm{V}$ \\
\hline \multirow{2}{*}{ SPhA } & Frumkin isotherm; $a=1.6 \pm 0.2$ & $\begin{array}{c}\text { Frumkin isotherm; } a=2.1 \pm 0.3 \\
\left(-\Delta G_{\mathrm{A}}^{0}\right)=16.8 \pm 0.3 \mathrm{~kJ} / \mathrm{mol}\end{array}$ \\
\hline \multirow{2}{*}{ SFPh } & Temkin isotherm; $f=2.0 \pm 0.3$ & Temkin isotherm; $f=2.17 \pm 0.45$ \\
& $\left(-\Delta G_{\mathrm{A}}^{0}\right)=56.4 \pm 0.1 \mathrm{~kJ} / \mathrm{mol}$ & $\left(-\Delta G_{\mathrm{A}}^{0}\right)=49.6 \pm 0.1 \mathrm{~kJ} / \mathrm{mol}$ \\
\hline \multirow{2}{*}{$\mathrm{SMePh}$} & Frumkin isotherm; $a=0.3 \pm 0.1$ & Frumkin isotherm; $a=1.3 \pm 0.1$ \\
& $\left(-\Delta G_{\mathrm{A}}^{0}\right)=40.50 \pm 0.02 \mathrm{~kJ} / \mathrm{mol}$ & $\left(-\Delta G_{\mathrm{A}}^{0}\right)=27.25 \pm 0.04 \mathrm{~kJ} / \mathrm{mol}$ \\
\hline \multirow{2}{*}{$\mathrm{SDF}$} & Temkin isotherm; $f=3.1 \pm 1.2$ & Temkin isotherm; $f=4.0 \pm 0.5$ \\
& $\left(-\Delta G_{\mathrm{A}}^{0}\right)=45.7 \pm 0.2 \mathrm{~kJ} / \mathrm{mol}$ & $\left(-\Delta G_{\mathrm{A}}^{0}\right)=46.00 \pm 0.06 \mathrm{~kJ} / \mathrm{mol}$ \\
\hline
\end{tabular}

It is unlikely that the charge of the electrode/solution interface at $E=-0.65 \mathrm{~V}$ is more positive than at $E=+0.2 \mathrm{~V}$, therefore, it is not unreasonable to assume that the chemisorption ability of a "clean" iron surface is higher than that of oxidized iron. ${ }^{2}$ This assumption is corroborated by the fact that incorporation of substituents in the second aromatic ring of SPhA more strongly intensifies the adsorption of substituted $\mathrm{SPhAs}$ on non-oxidized iron surface.

$\mathrm{SFPh}$ is the best CI among the substituted SPhAs studied, that is why it was studied in more detail. Based on a comparison of the adsorption isotherms and $\left(-\Delta G_{\mathrm{A}}^{0}\right)$ values obtained on various electrodes (Tables 3 and 4), it can be concluded that its adsorption on mild steel surfaces occurs with more difficulty than on the surface of zone-melted iron and a higher concentration of $\mathrm{CI}$ is required to form one monomolecular layer [53]. For example, at $E=-0.65 \mathrm{~V}$, whereas SFPh adsorption on pure iron is described by Eq. (3) with $\left(-\Delta G_{\mathrm{A}}^{0}\right)=56.4 \mathrm{~kJ} / \mathrm{mol}$, adsorption on Armco iron and $\mathrm{St} 3$ steel is described by Eq. (7) with $\left(-\Delta G_{\mathrm{A}}^{0}\right)=36.8$ and $23.1 \mathrm{~kJ} / \mathrm{mol}$, respectively. It can be assumed that the impurities present in mild steels do not have the same adsorption activity as the active centers of pure iron, which promote chemisorption of the organic anions. However, SFPh chemisorption even occurs on mild steel, as was established by the results of XPS investigations of thin films formed by these CIs on mild steel. In this respect, SFPh is a convenient object for studies because it contains a $\mathrm{CF}_{3}$-group, which serves as a kind of mark in XPS studies of the $\mathrm{CI}$ adsorption on a metal.

\footnotetext{
${ }^{2}$ A similar effect was observed in studies of other efficient organic CIs for iron and steel, e.g., sodium dioctyl phosphate (SDOPh) [51] and sodium octylphosphonate (SOP) [52].
} 
Table 4. Adsorption constants and free adsorption energies of SFPh for its adsorption at reduced $(E=$ $-0.65 \mathrm{~V})$ and oxidized electrode $(E=0.2 \mathrm{~V})$ from borate buffer solution ( $\mathrm{pH} 7.36)$

\begin{tabular}{ccc}
\hline Electrode & $\boldsymbol{E}=\mathbf{- 0 . 6 5} \mathbf{~ V}$ & $\boldsymbol{E}=\mathbf{0 . 2} \mathbf{~ V}$ \\
\hline \multirow{2}{*}{ Armco iron } & Frumkin isotherm; $a=0.3 \pm 0.1$ & Frumkin isotherm; $a=1.4 \pm 0.1$ \\
& $\left(-\Delta G_{\mathrm{A}}^{0}\right)=36.8 \pm 1.8 \mathrm{~kJ} / \mathrm{mol}$ & $\left(-\Delta G_{\mathrm{A}}^{0}\right)=20.4 \pm 1.0 \mathrm{~kJ} / \mathrm{mol}$ \\
\hline \multirow{2}{*}{ St3 steel } & Frumkin isotherm; $a=1.5 \pm 0.1$ & Frumkin isotherm; $a=1.0 \pm 0.1$ \\
& $\left(-\Delta G_{\mathrm{A}}^{0}\right)=23.1 \pm 0.1 \mathrm{~kJ} / \mathrm{mol}$ & $\left(-\Delta G_{\mathrm{A}}^{0}\right)=21.1 \pm 1.1 \mathrm{~kJ} / \mathrm{mol}$ \\
\hline
\end{tabular}

Investigations performed by L.P. Kazansky using XPS with angular resolution made it clear that the film thickness is less than $2-3 \mathrm{~nm}$, since the metallic peak is distinctly visible in the $\mathrm{Fe} 3 p$ spectrum [54]. Figure 9a presents the dependences of the ratio of the relative intensity of peaks for $\mathrm{F} / \mathrm{N}$ and $\left(\mathrm{Fe}^{3+}+\mathrm{Fe}^{2+}\right) / \mathrm{Fe}^{0}$ on the exit angle of the electrons. The deflections of the experimental and calculated values can be determined from the surface roughness and scatter of the introduced data for the calculated model. The experimentally obtained angular dependence of the peak intensities indicates the preferred orientation of SFPh anions, at which carboxyl oxygen is bound by the iron cation and the anion is directed away from the surface. It can be assumed that the molecules are located vertically and form a self-organizing molecular layer (Figure 9b). In this layer, the molecules hold each other by $\pi$-interactions of the benzene rings, which promotes stronger adsorption on the steel surface.
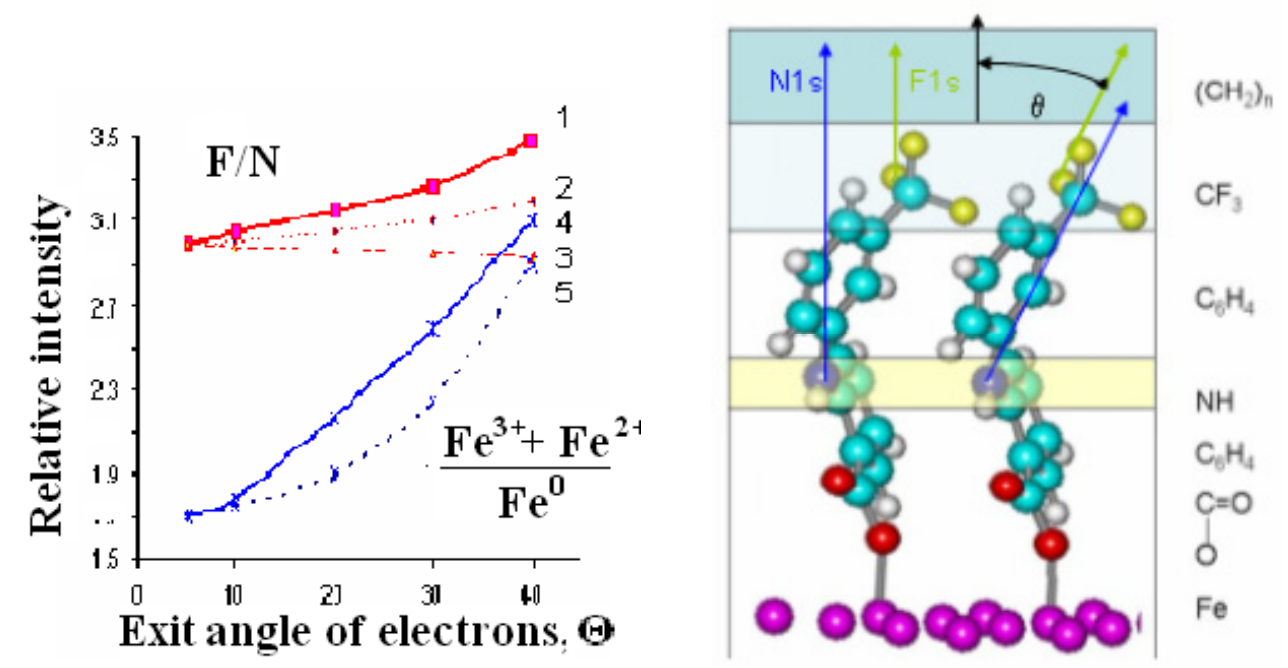

Figure 9. a) Angular dependence of ratios of relative intensities $\mathrm{Fe}(\mathrm{ox}) / \mathrm{Fe}(\mathrm{m}), \mathrm{F} / \mathrm{N}$ and $\mathrm{Fe} / \mathrm{C}$ at different angle $\alpha$ normalized to the same ratio determined at angle $\alpha=0^{\circ}$ (closed symbols experimental data $(1,2)$, broken line - calculated for a model; 3 - at random orientation of $\mathrm{SFlPh} ; 4,5$ - at vertical orientation on surface). b) Assumed orientation of SFPh molecules on the mild steel surface. 
SFPh is also of interest because it is a good CI for non-ferrous metals, zinc in particular. The study of SFPh adsorption from aqueous borate solution on zinc surface reported in [55] was also carried out using a combination of ellipsometry and XPS. It is well known that the nature of passive films formed on zinc can play a major role in inhibitor adsorption. In accordance with [56], zinc passivation is characterized by the formation of $\mathrm{Zn}(\mathrm{OH})_{2}$ or $\mathrm{ZnO}$ films in borate solutions, which are often used as a model background in the examination of the anodic behavior of metals. Other investigations [57, 58] considered a double-layer model of passive film with a thin compact layer located under a porous oxide.

$\mathrm{SFPh}$ adsorption on zinc surface is more efficient in weakly alkaline medium where the oxyhydroxide film is thinner than in neutral solution. The high values of free SFPh adsorption energy in neutral solution $\left(-\Delta G_{\mathrm{A}}^{0}\right)=57.8 \mathrm{~kJ} / \mathrm{mol}$ and especially in weakly alkaline solution $\left(-\Delta G_{\mathrm{A}}^{0}\right)=61 \mathrm{~kJ} / \mathrm{mol}$ enabled us to assume chemisorption of the CI on zinc. Irreversible SFPh adsorption on a zinc surface was confirmed by XPS investigations that detected a practically vertical orientation of adsorbed SFPh particles with respect to the surface.

$\mathrm{SFPh}$ is well compatible with other efficient CIs, and mixtures with this inhibitor may be better than well-known synergistic compositions based on SPhA [50]. For example, replacement of SPhA for SFPh combined with sodium oleate (SOl) increases the adsorbability of the mixture on iron (Figure 10a) [59]. Their adsorption on a reduced iron surface $(E=-0.65 \mathrm{~V})$ is described by the Temkin isotherm with a high $\left(-\Delta G_{\mathrm{A}}^{0}\right)=51.8$ and $60.35 \mathrm{~kJ} / \mathrm{mol}$ for mixtures based on SPhA and SFPh, respectively. It is significant that the combination exhibits synergism of adsorption not only during passivation but also in the prevention of local depassivation of iron by corrosive anions (Figure 10b). There is no doubt that we are dealing with the chemisorption of these CIs and, unsurprisingly, that an equimolar mixture of SFPh with $\mathrm{SOl}$ is a stronger passivator than its components [53].
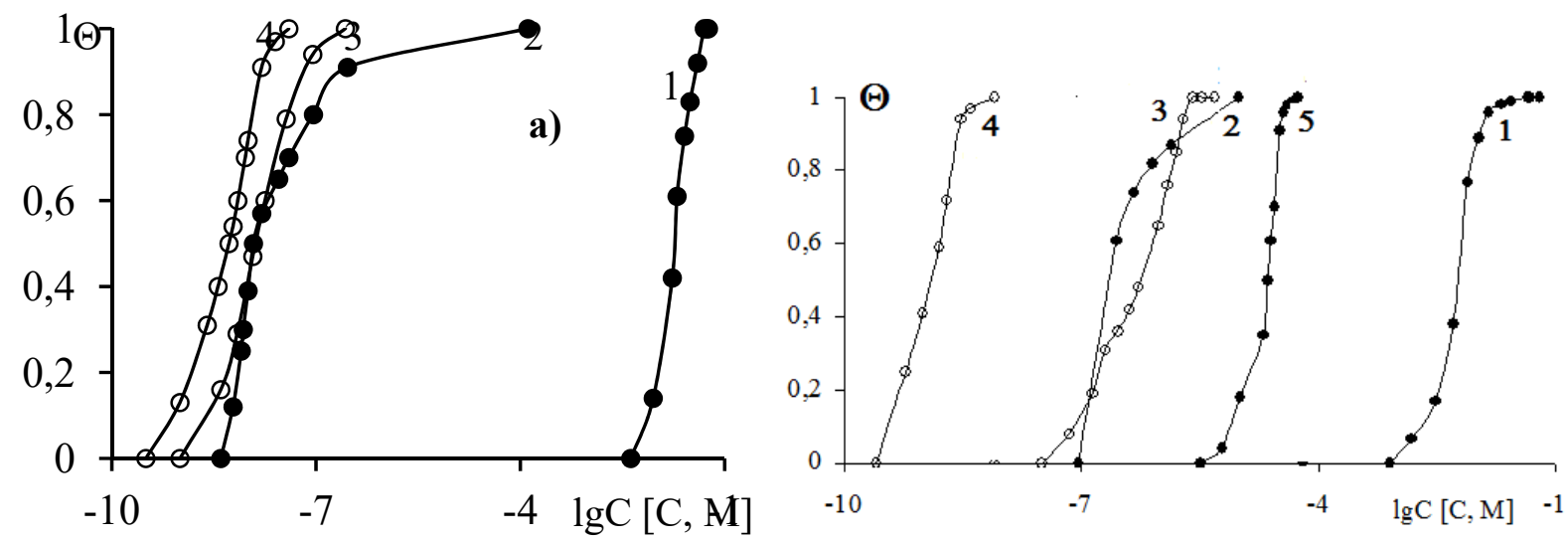

Figure 10. Isotherms of CI adsorption on reduced zone-melted iron at $E=-0.65 \mathrm{~V}$ (a) and passive iron at $E=0.2 \mathrm{~V}(\mathrm{~b}): 1-\mathrm{SPhA} ; 2-\mathrm{SFPh} ; 3-\mathrm{SPhA}+\mathrm{SOl} ; 4-\mathrm{SFPh}+\mathrm{Sol} ; 5-\mathrm{Sol}$. 
Of particular interest is the combination of SFPh with 5-chloro-1,2,3-benzotriazole (5Cl-BTA), adsorption of which is well studied, and the triazole itself is an excellent CI for various metals and alloys in neutral media [60-65]. Authors [65] proposed formal adsorption isotherms described by Eq. (7) from dependences of $(-\delta \Delta)$ on $\log C_{\text {in }}$ obtained at $E=0.2 \mathrm{~V}$, assuming that flattening out corresponds to coverage degree $\theta \rightarrow 1.0$. For 5Cl-BTA, $\left(-\Delta G_{\mathrm{A}}^{0}\right)=37.4 \pm 1.9 \mathrm{~kJ} / \mathrm{mol}$, which substantially exceeds the same value for BTA $\left(-\Delta G_{\mathrm{A}}^{0}\right)=26.5 \pm 1.3 \mathrm{~kJ} / \mathrm{mol}$. Comparison of a 5-Cl-BTA mixture with SFPh (Figure 11) at the same ratio of components $(2: 3)$ showed its advantage over the mixture of BTA with $\mathrm{SFPh}$. The combination of 5-Cl-BTA with SFPh is adsorbed on oxidized steel surface substantially better than not only SFPh, but also the triazole component or the similar mixture of BTA with SFPh. Its adsorption isotherm is adequately described by Eq. (7) with $a=1.72 \pm 0.23$ and $\left(-\Delta G_{\mathrm{A}}^{0}\right)=58.5 \pm 2.9 \mathrm{~kJ} / \mathrm{mol}$. This combination has an advantage, even if small, over the combination of SFPh with BTA, the adsorption characteristics of which are as follows: $a=1.93 \pm 0.13$ and $\left(-\Delta G_{\mathrm{A}}^{0}\right)=53.5 \pm 2.6 \mathrm{~kJ} / \mathrm{mol}$.

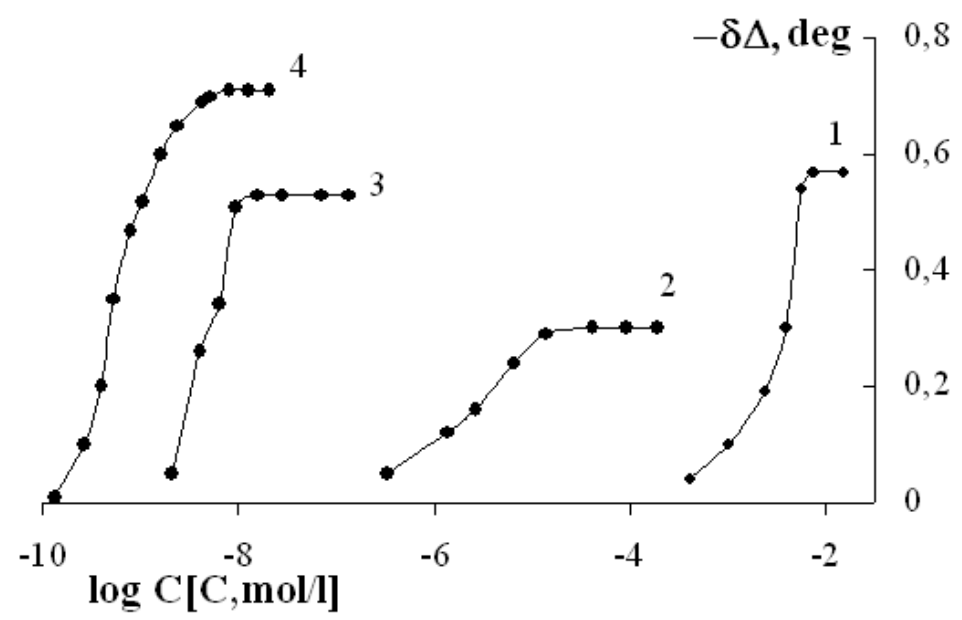

Figure 11. Dependence of changes in ellipsometric angle $\Delta$ on the concentrations of $\mathrm{SFPh}(1)$, 5-Cl-BTA on an SFPh monolayer (2), BTA + SFPh (2:3) (3), and 5-Cl-BTA + SFPh (4) on St3 steel surface oxidized at $E=0.2 \mathrm{~V}$.

Amplification of the adsorption properties of 5-Cl-BTA (similarly to BTA) in combination with the carboxylate can be caused by the formation of associates by the mixed components, which are capable of adsorbing at lower concentrations. However, a significant difference is observed between BTA and 5-Cl-BTA. BTA itself is not adsorbed on a SFPh monolayer, whereas 5-Cl-BTA is adsorbed even more easily on such an electrode than on oxidized steel surface itself. The adsorption isotherm obtained in this case is described by Eq. (7) with $a=0.95 \pm 0.23$ and $\left(-\Delta G_{\mathrm{A}}^{0}\right)=39 \pm 2.0 \mathrm{~kJ} / \mathrm{mol}$. The $a$ values characterizing the interaction force between 5-Cl-BTA molecules during adsorption on oxide and on its surface modified by adsorption of a SFPh monolayer are quite close $(a=1.18 \pm 0.15$ for 5 -Cl-BTA on St3 at $E=0.2 \mathrm{~V})$. 
Additional information about the structure of the adsorption layers of various chemical compounds can be obtained from XPS investigations, despite the fact that, in contrast to ellipsometry, the technique used to obtain XPE spectra does not allow one to control the potential of the metal and this is an ex situ method. At the same time, the high strength of the adsorption bonds estimated by preliminary ellipsometric investigations allows one to hope that these bonds would be deformed only slightly upon electrode removal from solution and that it would be possible to estimate them correctly, albeit of course with certain approximations of the adsorption film composition and structure.
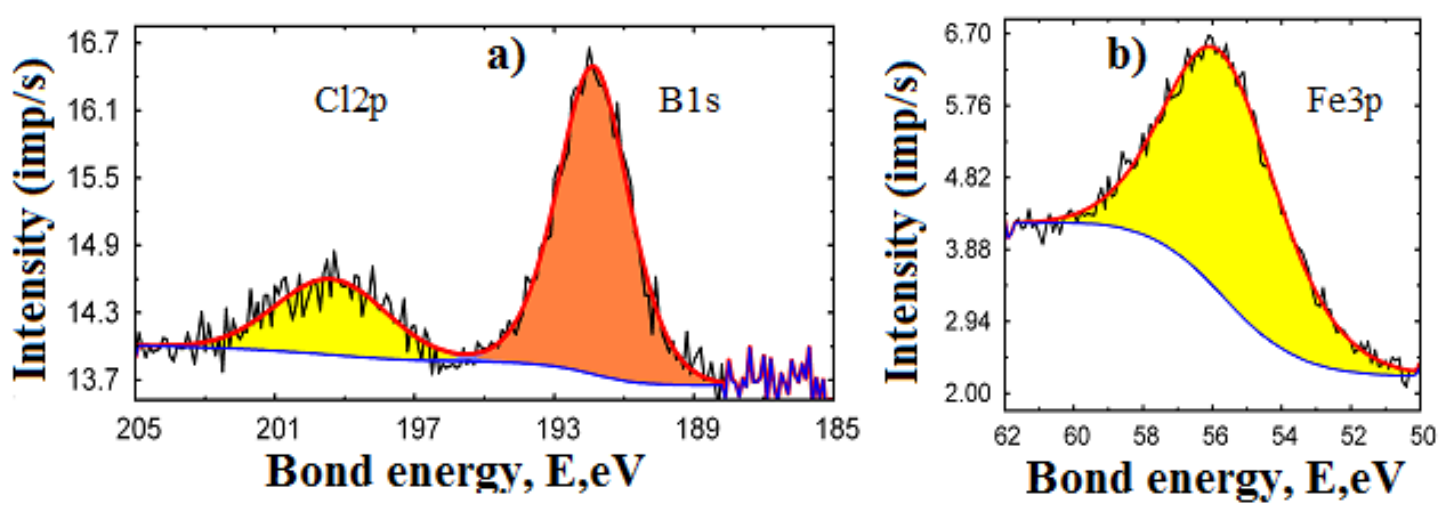

Figure 12. XPE-spectra of $\mathrm{Cl} 2 p, \mathrm{~B} 1 s$ (a) and $\mathrm{Fe} 3 p$ electrons (b) of St 3 steel surface held in borate solution at $E=0.2 \mathrm{~V}(5-\mathrm{Cl}-\mathrm{BTA})$.

The presence of various heteroatoms $(\mathrm{N}, \mathrm{O}, \mathrm{F}$ and $\mathrm{Cl})$ serving as certain marks in $\mathrm{XPE}$ spectra in adsorbate molecules (SFPh and 5-Cl-BTA) is quite an important factor. Analysis of the XPE spectra of St3 samples kept in borate buffer with 5-Cl-BTA concentration corresponding to monolayer coverage of the surface by the $\mathrm{CI}(\log C=-4.00)$ at $E=0.2 \mathrm{~V}$ showed that, apart from 5-Cl-BTA molecules, borate is incorporated (Figure 13a). 5-Cl-BTA is located on the FeOOH surface, since the spectrum type of $\mathrm{Fe} 2 p$ and $\mathrm{Fe} 3 p$ electrons (for Fe $3 p, E_{\mathrm{b}}=56.3 \mathrm{eV}$ ) (Figure 13b) is similar to the spectra obtained for the pure St3 surfaces. According to calculations, the 5-Cl-BTA layer thickness is $0.4 \pm 0.1$ $\mathrm{nm}$. Based on data of the angular dependence of the peak intensity ratio of $\mathrm{Cl} 2 p$ and $\mathrm{N} 1 s$ electrons, $\mathrm{Cl}$ atoms are located farther from the oxide surface than $\mathrm{N}$ atoms. The peak position of N1s electrons $\left(E_{\mathrm{b}}=400.3 \mathrm{eV}\right)$, which is lower than the value obtained for the initial 5-Cl-BTA (401.1 eV) and higher than for ionized molecule in the sodium salt $(399.6 \mathrm{eV})$, points to the fact that 5-Cl-BTA forms a chemical bond with the surface iron cations through $\mathrm{N}$ atoms. It follows that 5-Cl-BTA molecules occupy an almost vertical position relative to the steel surface.

In the case of an St3 sample kept in borate solutions containing an equimolar mixture of $\mathrm{FPh}$ (SFPh anion) and 5-Cl-BTA, a certain excess of the latter $(\mathrm{FPh}: 5-\mathrm{Cl}-\mathrm{BTA}=$ $1: 1.25)$ is observed if we consider that a mixed layer is formed on the steel surface. A better adsorption of triazole in comparison with $\mathrm{SFPh}$ is a possible reason for such an increase in 5-Cl-BTA amount over SFPh on the surface from the mixture. The calculated 
thickness of such a mixed layer is $0.71 \mathrm{~nm}$. This value is close to the average value of the $\mathrm{FPh}$ anion length, vertical orientation of which was determined previously [54], and 5-ClBTA calculated through the lengths of bonds composing them $(\sim 1.15 \mathrm{~nm}$ and $\sim 0.6 \mathrm{~nm}$, respectively). This value was obtained for planar layers, and it can be slightly different with consideration of surface roughness.
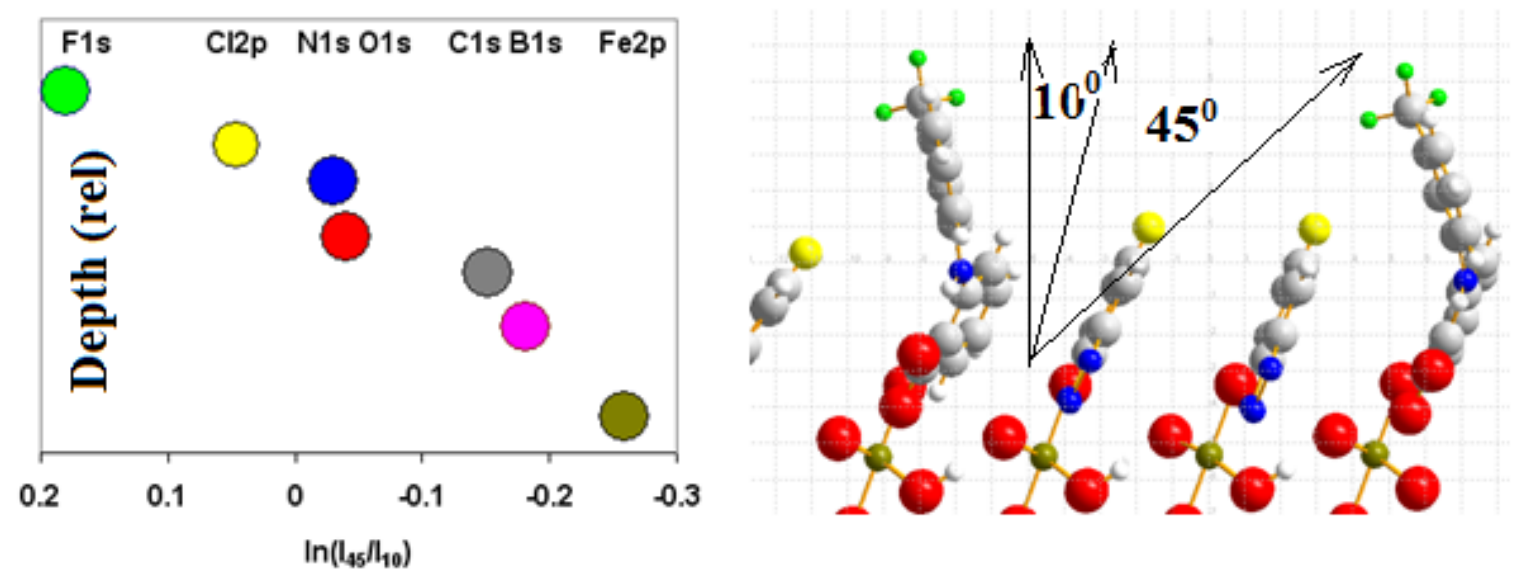

Figure 13. Relative depth distribution of atoms and (a) possible location of SFPh and 5-ClBTA on St3 surface (b) held in borate solution of $\mathrm{pH} 7.4$ (arrows indicate the direction of electron exit at two various angles of the relative surface normal).

To determine the arrangement of elements through the thickness of the surface layer, a simple approach in which the ratio of peak intensities of the element at two exit angles of the electrons is used. It is known that peak intensity $I_{0}$ determined by atoms lying at a depth lower than $d$ decreases to intensity $I$ according to the equation:

$$
I=I_{0} \exp (-d / \lambda \cos \theta)
$$

where $\lambda$ is mean free path of the ejected electron in the absorbing layer with $d$ thickness and $\theta$ is an exit angle of electrons relative to the surface normal [66]. If we use the intensities at various angles (in our case at $\theta_{1}=45^{\circ}$ and $\theta_{2}=10^{\circ}$ ), we obtain:

$$
-\ln \left(I_{1} / I_{2}\right)=d\left[\left(1 / \lambda \cos \theta_{1}\right)-\left(1 / \lambda \cos \theta_{2}\right)\right]
$$

where $\left(1 / \lambda \cos \theta_{1}\right)-\left(1 / \lambda \cos \theta_{2}\right)$ is constant. The logarithm of the ratio of the intensities then leads to relative value $d$. Since the absolute value of thickness depends on the $\lambda$ value, which is determined by many parameters, such as the kinetic energy of electrons, compound density, etc., it can influence the $d$ value. In addition, if atoms of the same element are located at various depths, then the position of the point on the graph of relative depths will be averaged, as for carbon, which forms the surface layer.

Figure 13a shows that $\mathrm{F}$ atoms are located higher than are $\mathrm{Cl}$ atoms and especially higher than $\mathrm{N}$ atoms. Unfortunately, the accuracy of the data does not allow one to calculate the depths at which the corresponding atoms are located, but it is natural that iron cations are located lower than the others and form a substrate for the overlying mixed 
layer. Based on the distribution of the elements by the depth of the location, a model of 5Cl-BTA and FPh anions on a FeOOH surface (100 orientation) can be proposed. According to this model, the molecules under investigation are located almost vertically to the surface (Figure 13b).

In the case of a layer-by-layer coating of 5-Cl-BTA on an SFPh monolayer, we obtain a two-layer nanofilm. During its analysis, changes are visible in the XPE spectra, the angular dependence of which points that $\mathrm{Cl}$ and $\mathrm{N}$ atoms are located higher than $\mathrm{F}$ atoms. Based on this, it can be assumed that 5-Cl-BTA molecules are located higher than the $\mathrm{SFPh}$ layer. A calculation of the thicknesses gives $0.8-1.0 \mathrm{~nm}$ for $\mathrm{SFPh}$ and no more than $0.2 \mathrm{~nm}$ for 5-Cl-BTA.

The thicknesses of the monolayers formed by the CIs under investigation were also calculated from the ellipsometry results. As is seen from Table 5, agreement between the calculations by various methods is not observed for all CIs. A possible reason for such a difference is that all ellipsometric measurements are performed in situ, whereas XPES investigations involve the sample removal (ex situ), washing it with a water stream, and treatment in an ultrasonic bath. If we assume that 5-Cl-BTA molecules are located on a surface formed by $\mathrm{CF}_{3}$-groups, using data of XPES and ellipsometry, the inclination angle of the molecules $(\alpha)$ to this virtual surface can be determined by the equation:

$$
\sin \alpha=\text { layer thickness / molecule length }
$$

Consequently, the inclination angle of the 5-Cl-BTA molecule plane on a monolayer of SFPh molecules is $\approx 30^{\circ}$. At the same time, SFPh and 5-Cl-BTA particles adsorbed from a mixed CI solution are oriented almost vertically to the oxide surface, as it is shown in Figure 13b. Thus, a direct dependence between the molecule inclination angle to the surface and the nature of the latter, which can substantially affect the efficiency of the protective nanocoating, is revealed.

Table 5. Values of inhibitor monolayer thicknesses on St3 steel surface in neutral solution obtained by different methods of investigation.

\begin{tabular}{|c|c|c|}
\hline \multirow{2}{*}{ Corrosion Inhibitor } & \multicolumn{2}{|c|}{ Thickness calculation method, $\mathbf{n m}$} \\
\cline { 2 - 3 } & XPES & Ellipsometry \\
\hline SFPh & $0.9 \pm 0.1$ & $1.1 \pm 0.1$ \\
\hline 5-Cl-BTA & $0.4 \pm 0.1$ & $0.75 \pm 0.1$ \\
\hline 5-Cl-BTA + SFPh & $0.7 \pm 0.3$ & $0.8 \pm 0.1$ \\
\hline 5-Cl-BTA on SFPh monolayer & $0.2 \pm 0.1$ & $0.25 \pm 0.1$ \\
\hline
\end{tabular}

Successive adsorption of various organic CIs (formation of a "layer-by-layer coating") on the metal surface deserves special attention as a relatively new method of improving their absorption and protection of metals from corrosion. Even in [67] it was 
found that the phenomena of synergetic effect in the anti-corrosion protection of iron by mixtures of organic anions can be associated with the ability of one component to initiate the adsorption of the other one. The co-adsorption is characterized by a shift of the adsorption isotherm toward lower concentrations (by 1 to 2 orders of magnitude) and, probably, by a stronger bonding with the metal surface. This case is fundamentally different from the long-known effect of pre-adsorption of anions (sulfoacids of the fatty or aromatic series, $\mathrm{I}^{-}, \mathrm{Br}^{-}, \mathrm{Cl}^{-}, \mathrm{CNS}^{-}, \mathrm{HS}^{-}$, etc.) that recharges the electrode surface and facilitates subsequent adsorption of large organic cations on it [68].This situation offered a new possibility: to construct extremely thin nanodimensional coatings only by an electrochemical technology, while monitoring the adsorption in situ by ellipsometry.

Already the first study in this area yielded interesting results (Figure 14) that were discussed in detail in our report at the $8^{\text {th }}$ International Frumkin Conference [69]. In this investigation, we measured adsorption of $\mathrm{SPhU}$ (sodium phenyl undecanate $\mathrm{C}_{6} \mathrm{H}_{5}\left(\mathrm{CH}_{2}\right)_{10} \mathrm{COONa}$ ) and $\mathrm{SMePh}$ (sodium mephenaminate $\left(\mathrm{CH}_{3}\right)_{2} \mathrm{C}_{6} \mathrm{H}_{3} \mathrm{NHC}_{6} \mathrm{H}_{4} \mathrm{COONa}$ ) from borate buffer with $\mathrm{pH} 7.4$ on passive iron at $E=0.2 \mathrm{~V}$ using ellipsometry (Figure 14). It was shown that preliminary adsorption of $\mathrm{SPhU}$, which is equivalent to its monolayer, can stimulate an increase in $\left(-\Delta G_{\mathrm{A}}^{0}\right)$ for $\mathrm{SMePh}$ adsorption. Moreover, if $\mathrm{SPhU}$ is adsorbed on an electrode with such a double-layer film, the value of its $\left(-\Delta G_{\mathrm{A}}^{0}\right)$ also increases. Further studies have shown that successive treatment of St3 plates with solutions of SPhU, $\mathrm{SMePh}$, and again $\mathrm{SPhU}$ extends the time of complete protection compared to treatment with a SPhU $+\mathrm{SMePh}$ solution [70]. Later it was shown [71] that preliminary adsorption of SPhU on oxidized iron induced BTA adsorption at lower concentrations.

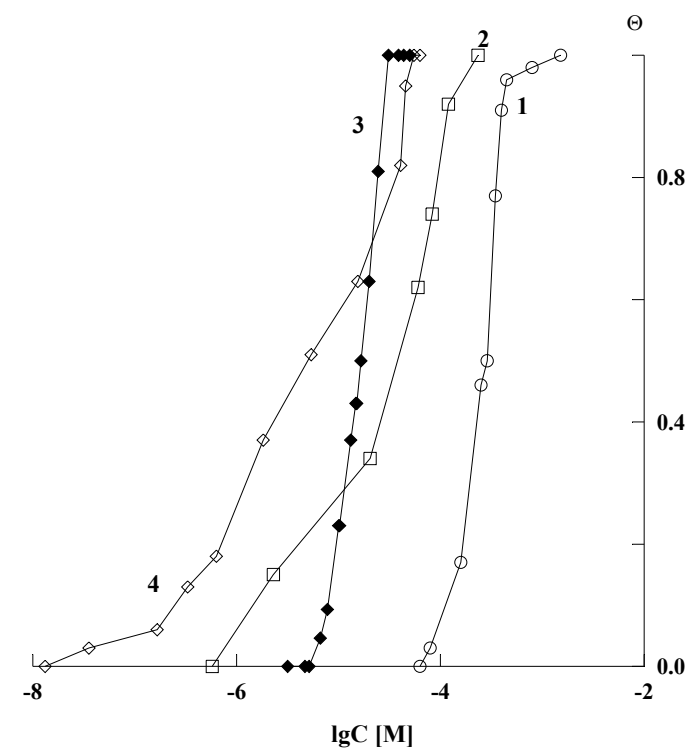

Figure 14. Adsorption isotherms of sodium salts of organic acids and their mixtures on oxidized iron surface at $E=0.2 \mathrm{~V}$ : (1) $\mathrm{SMePh}$ without and (2) with preliminary adsorption of SPhU, and (3) SPhU without and (4) with preliminary formation of a two-layered coating consisting of $\mathrm{SPhU}$ and $\mathrm{SMePh}$. 
However, a high coverage $(\Theta)$ with preadsorbed anions does not always beneficially affect subsequent adsorption of another CI. When studying BTA adsorption as a function of $\Theta$ with preadsorbed SFPh, we found that BTA adsorption depends on $\Theta_{\text {SFPh }}$ in a nonlinear manner. In particular, when $\mathrm{SFPh}$ forms a preliminary monolayer on a steel surface, BTA is not adsorbed on it. However, BTA adsorption increases, approaching the optimal coverage, when the pre-adsorption of SFPh comes to $\Theta_{\mathrm{SFPh}}=0.1-0.33$, and $\left(-\Delta G_{\mathrm{A}}^{0}\right)$ can reach up to $58.7 \mathrm{~kJ} / \mathrm{mol}$ in this case. We may suggest that attraction between vertically oriented SFPh anions and BTA particles becomes easier when the triazole adsorption on unoccupied steel surface occurs, due to the lateral interaction of their aromatic rings.

A similar effect was observed upon pre-adsorption of disodium salt of 2,4-di(1metoxyethyl)deuteroporphyrin IX, dimegin (DMG) on a passive iron surface [72]. Dimegin adsorption on iron, steel and copper from a borate buffer solution with $\mathrm{pH} 7.4$ is adequately described by Eq. (3), with the values of $f$ and $\left(-\Delta G_{\mathrm{A}}^{0}\right)$ of 1.0 and $43 \mathrm{~kJ} / \mathrm{mol} ; 2.2$ and $51 \mathrm{~kJ} / \mathrm{mol} ; 3.4$ and $56 \mathrm{~kJ} / \mathrm{mol}$, respectively, which gives reason to believe it to be chemisorption on oxidized electrodes [73]. Consequently, dimegin can be used to modify the electrode surface in order to improve subsequent adsorption thereon of other known CIs. It was shown that such modification of steel surface can enhance adsorption of BTA on passive electrode, which is also described by the Temkin equation [72]. The adsorption characteristics of BTA depend on $\Theta_{\mathrm{DMG}}$. Upon transition to the modified surface, the factor of its heterogeneity and $\left(-\Delta G_{\mathrm{A}}^{0}\right)$ initially increases (to $\Theta_{\mathrm{DMG}} \sim 0.5$ ) and then decreases.

In the case of modification of the copper electrode surface by pre-adsorption of dimegin already at $\Theta_{\mathrm{DMG}}$, the adsorption of BTA is characterized by an increase in $f$ and $\left(-\Delta G_{\mathrm{A}}^{0}\right)$ from 2.4 to 5.4 and from 58 to $63 \mathrm{~kJ} / \mathrm{mol}$, respectively [73]. The results of a study of dimegin adsorption with the use of ellipsometry and XPS allow us to suggest that coordination of carboxyl groups of dimegin to copper and formation of a bridge over several copper cations occur (Figure 15), since the distance between the nearest oxygen atoms of two carboxyl groups could be more than $3 \mathrm{~nm}$. The presence of side substituents does not favor the planar arrangement of the molecules on the copper surface. Since the maximum size of the dimegin molecule is $\sim 1.44 \mathrm{~nm}$, it can be assumed that dimegin anions are arranged at an angled position (with an angle of $\sim 45^{\circ}$ or less) to the $\mathrm{Cu}_{2} \mathrm{O}(100)$ surface.

Suppose that dimegin molecules form certain clusters that occupy the active sites of the surface. The open part of the surface can be occupied by different molecules that can substantially increase the protective properties of such complex surface layer. It is possible that small BTA molecules penetrate the dimegin layer, not only occupying the empty sites on the surface but also interacting by means of $\pi$-bonding between the heterocycles. Such adsorption results in highly desirable synergism in action of the two molecules.

The conclusion that the protective action of BTA depends on $\Theta_{\mathrm{SFPh}}$ was confirmed by corrosion tests in humid atmosphere with forced daily water condensation on the steel surface. Dilute BTA or SFPh solutions $(3 \mathrm{mmol} / \mathrm{l})$ do not efficiently passivate steel. The 
protective action is somewhat strengthened in the inhibitor mixture and corrosion becomes visible after $\tau=5.8$. The best result is achieved by two-stage adsorption where $\Theta_{\mathrm{SFPh}}=$ 0.33 , followed by treatment of the surface with a BTA solution. In this case, $\tau=10$ days, whereas at $\Theta_{\mathrm{SFPh}}=0.5$ the protection time is two times smaller.

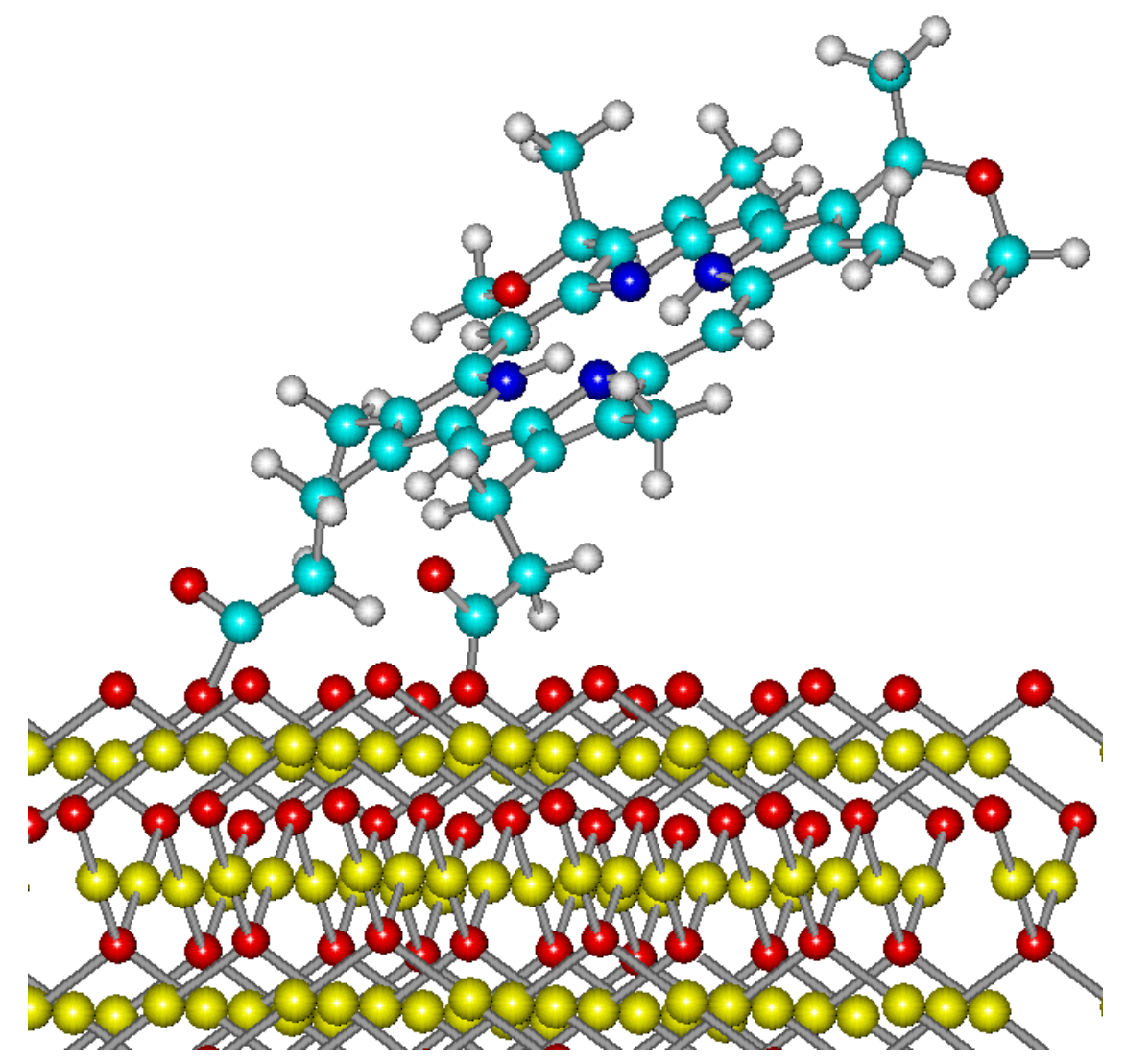

Figure 15. Dimegin molecule on $\mathrm{Cu}_{2} \mathrm{O}(100)$ (a fragment).

The advantages of the proposed method of passivation of metals will be discussed in more detail in the second part of this review. Here we only note that it can be successfully used on various metals and alloys. Besides, preliminary surface treatment (modification) can give excellent results if not only the CIs capable of chemisorption on the metal are used but also CIs that can form complexes with cations of other metals, e.g., zinc or copper phosphonates. In this case, the mechanism of CI interaction with the metal surface is even more complex. 


\section{References}

1. G. Trabanelli, Corrosion, 1991, 47, no. 6. 410.

2. A. Frignani, M. Tassinari, L. Meszaros and G. Trabanelli, Corros. Sci., 1991, 32, no. 8, 903.

3. Z. A. Jofa, V. V. Batrakov and Cho Ngok Ba, Electrochim. Acta, 1964, 9, no. 8, 1645.

4. B. B. Damaskin, O. A. Petrii and V. V. Batrakov, Adsorption of Organic Compounds on Electrodes, New York, Plenum Press, 1971.

5. N. Hackerman and E. McCafferty. Proc. $5^{\text {th }}$ Intern. Congress on Metallic Corrosion, 1974, vol. 4, 542.

6. N. I. Podobaev and N. E. Novikov, Prot. Met., 1974, 14, 1030.

7. S. M. Reshetnikov, Ingibitory kislotnoi korrozii metallov (Inhibitors of acid corrosion of metals), 1986, Khimiya, Leningrad (in Russian).

8. E. Lazarova, G. Petkova and G. Neykov, Proc. $9^{\text {th }}$ Europ. Symp. on Corros. and Scale Inhibitors, Ferrara, Italy, 2000, vol. 1, 179.

9. M. Lagrenée, M. Lebrini, F. Bentiss and H. Vezin, Proc. $10^{\text {th }}$ Europ. Symp. on Corros. and Scale Inhibitors, Ferrara, Italy, 2005, vol. 1, 117.

10. M. Lebrini, M. Lagrenée, H. Vezin, L. Gengembre and F. Bentiss, Corros. Sci., 2005, 47, 485.

11. Yu. I. Kuznetsov, N. N. Andreev and S. S. Vesely, Int. J. Corros. Scale Inhib., 2015, 4, no. 2, 108. doi: 10.17675/2305-6894-2015-4-1-108-109

12. X. H. Li, S. D. Deng and H. Fu, Corros. Sci., 2009, 51, 1344.

13. A. Samide, B. Tutunaru and C. Negrilab, Chem. Biochem. Eng. Q., 2011, 25, no. 3, 123.

14. F. Bentiss, M. Outirite, M. Traisnel, H. Vezin, M. Lagrenée, B. Hammouti, S. S. AlDeyab and C. Jama, Int. J. Electrochem. Sci., 2012, 7, 1699.

15. M. Tourabi, K. Nohair, M. Traisnel, C. Jama and F. Bentiss, Corros. Sci., 2013, 75, 299.

16. Y. Tang, F. Zhang, S. Hu, Z. Cao, Zh. Wu and W. Jing, Corros. Sci., 2013, 74, 271.

17. L. V. Frolova, Yu. I. Kuznetsov and O. O. Zel', Prot. Met. Phys. Chem. Surf., 2009, 45, no. 7, 796 .

18. Ya. G. Avdeev, P. A. Belinskii, Yu. I. Kuznetsov, and O. O. Zel', Prot. Met. Phys. Chem. Surf., 2010, 49, no. 7, 782.

19. Ya. G. Avdeev, A. Yu. Luchkin and Yu. I. Kuznetsov, Korroz.: Mater. Zashch., 2011, no. 10, 23 (in Russian).

20. Ya. G. Avdeev and Yu. I. Kuznetsov, Russ. Chem. Rev., 2012, 81, no. 8, 1133.

21. Ya. G. Avdeev, M. V. Tyurina, Yu. I. Kuznetsov, Yu. E. Pronin and L. P. Kazansky, Korroz.: Mater. Zashch., 2013, no. 6, 17 (in Russian).

22. Ya. G. Avdeev, A. Yu. Luchkin and Yu. I. Kuznetsov, Prot. Met. Phys. Chem. Surf., 2013, 49, no. 7, 865 . 
23. Ya. G. Avdeev, M. V. Tyurina and Yu. I. Kuznetsov, Int. J. Corros. Scale Inhib., 2014, 3, no. 4, 246. doi: 10.17675/2305-6894-2014-3-4-246-253

24. Ya. G. Avdeev, A. Yu. Luchkin, M. V. Tyurina and Yu. I. Kuznetsov, Korroz.: Mater. Zashch., 2015, no. 1, 23 (in Russian).

25. N. A. Kolpakova and T. S. Minakova, Termodinamika $i$ kinetika sorbtsionnogo kontsentrirovaniya (The Thermodynamics and Kinetics of Sorption Concentration), Tomsk Polytechn., Univ., Tomsk, 2011, part 1, pp. 51-55, 143-146 (in Russian).

26. T. V. Kartashova, A. V. Vvedenskii and E. V. Bobrinskaya, Kondens. Sredy Mezhfaz. Granitsy, 2005, 7, 3, 255 (in Russian).

27. S. Z. Roginsky and J. Zeldovich, Acta Physicochim. U.R.S.S., 1934, 1, no. 3/4, 554.

28. Ya. G. Avdeev, Yu. I. Kuznetsov, M. V. Tyurina, Korroz.: Mater. Zashch., 2012, no. 5, 22 (in Russian).

29. J. O'M. Bockris, M.A. Habib and J. L. Carbajal, J. Electrochem. Soc., 1984, 131, 3032.

30. J. O'M. Bockris, B. R. Scharifker and J. L. Carbajal, Electrochim. Acta., 1987, 32, 799.

31. N. P. Andreeva and Yu. I. Kuznetsov, Prot. Met., 1987, 23, no. 4, 601; 1989, 25, no. 2, 214.

32. L. A. Khanova, N. A. Zhuchkova and Z. L. Kudryavtseva, Soviet Electrochem., 1983, 19, no. 6, 710 .

33. F. H. P. Habraken, O. L. I. Gijzeman and G. A. Bootsma, Surf. Sci., 1980, 96, no. 1, 482.

34. S. V. Oleynick, Yu. I. Kuznetsov, S. S. Veselyi and M. G. Komakhidze, Russ. J. Electrochem., 1992, 28, no. 6, 693.

35. Yu. I. Kuznetsov, L. B. Maksaeva, M. A. Petrunin and N. P. Andreeva, Russ. J. Electrochem., 2009, 45, no. 11, 1240.

36. G. Sauerbrey, Zeitschrift für Physik, 1959, 155, no. 2, 206 (in German).

37. D. Jope, J. Sell, H. W. Pickering and K. G. Weil, J. Electrochem. Soc., 1995, 142, 2170.

38. M. Fonsati, F. Zucchi and G. Trabanelli, Electrochim. Acta, 1998, 43, 311.

39. A. Shaban, E. Kálmán and J. Telegdi, Electrochim. Acta, 1998, 43, 159.

40. J. Telegdi, A. Shaban and E. Kálmán, Electrochim. Acta, 2000, 45, 3639.

41. F. M. Al Kharafi, A. M. Abdullah and B. G. Ateya, J. Appl. Electrochem., 2007, 37, 1177.

42. F. M. Bayoumi, A. M. Abdullah and B. Attia, Mater. Corros., 2008, 59, no. 8, 691.

43. S. N. Ovchinnikova, T. P. Aleksandrova and A. A. Wais, Russ. J. Electrochem., 2005, 41, no. $11,1185$.

44. Hong Xuang and J. B. Schenoff, Langmuir, 1994, 10, 241.

45. Ch. Fruböse and K. Doblhofer, J. Chem.Soc. Faraday. Trans., 1995, 91, no. 13, 1949.

46. J. E. I. Wright, Kh. Fatih, Ch. L. Brosseau, S. Omanovic and Sh. G. Roscoe, J. Electroanal. Chem., 2003, 550-551, 41.

47. Ch. L. Brosseau and Sh. G. Roscoe, Electrochim. Acta, 2006, 51, 2145.

48. M. R. Tarasevich, A. Yu. Safronov, V. A. Bogdanovskaya and A. S. Chernyak, Soviet Electrochem., 1983, 19, no. 2, 227. 
49. Ya. G. Bober, Yu. I. Kuznetsov and N. P. Andreeva, Russ. J. of Electrochem., 2008, 44, no. 1,84 .

50. Yu. I. Kuznetsov, Organic Inhibitors of Corrosion of Metals, New York, Plenum Press, 1996.

51. A. A. Chirkunov, A. S. Gorbachev, Yu. I. Kuznetsov and N. P. Andreeva, Prot. Met. Phys. Chem. Surf., 2013, 49, no. 7, 854.

52. Y. I. Kuznetsov, A. A. Chirkunov, A. S. Gorbachev and N. P. Andreeva, Corros. Sci., 2015 (in press).

53. Y. I. Kuznetsov, Ya. G. Bober, N. P. Andreeva and L. P. Kazansky, The European Corrosion Congress EUROCORR-2008, Edinburgh, 2008, 1223.

54. L. P. Kazansky, Y. I. Kuznetsov, N. P. Andreeva and Ya. G. Bober, Appl. Surf. Sci., 2010, 257, 1166.

55. N. P. Andreeva, Yu. V. Ushakova, Yu. I. Kuznetsov, M. O. Agafonkina, L. P. Kazansky and Yu. Ya. Andreev, Prot. Met. Phys. Chem. Surf., 2014, 50, no. 7, 860.

56. E. E. Abd El Aal, Corros. Sci., 2000, 42, no. 1, 1.

57. S. Thomas, N. Birbilis, M. S. Venkatraman and I. S. Cole, Corrosion, 2012, 68, no. 1, 015009-1.

58. M. C. H. McKubre and D. D. Macdonald, J. Electrochem. Soc., 1981, 128, no. 3, 524.

59. Yu. I. Kuznetsov, Prot. Met. Phys. Chem. Surf., 2011, 47, no. 7, 821.

60. K. Aramaki, T. Kiuchi, T. Sumiyoshi and H. Nishihara, Corros. Sci., 1991, 32, 593.

61. F. Zucchi, G. Trabanelli and C. Monticelli, Corros. Sci., 1996, 38, no. 1, 147.

62. G. Bereket and A. Pinarbasi, Corros. Eng. Sci. Technol., 2004, 39, no. 4, 308.

63. A. Aranchibia, J. Henriques-Roman, M. A. Paez, I. Padila-Campos, J. H. Zagal, J. Costamagna and G. Cardenas-Jiron, J. Solid Electrochem., 2006, 10, 894.

64. L. P. Kazansky, I. A. Selyaninov and Yu. I. Kuznetsov, Appl. Surf. Sci., 2012, 259, 385.

65. M. O. Agafonkina, Yu. I. Kuznetsov, N. P. Andreeva, Yu. E. Pronin and L. P. Kazansky, Prot. Met. Phys. Chem. Surf., 2012, 48, no. 7, 773.

66. Practical Surface Analysis: Auger and X-Ray Photoelectron Spectroscopy, Eds. D. Briggs and M. P. Seah, New York, John Willey \& Sons, 1990, 1.

67. Yu. I. Kuznetsov and N. P. Andreeva, Prot. Met., 2005, 41, no. 6, 531.

68. Z. A. Jofa, Comptes Rendus du $2^{\text {eme }}$ Symposium Europeen sur les Inhibiteurs de Corrosion, Annali Univ. Ferrara, N.S., Sez., V, Suppl. 4, 1966, vol. 1, 93.

69. Yu. I. Kuznetsov and N. P. Andreeva, Russ. J. Electrochem., 2006, 42, no. 10, 1101.

70. Yu. I. Kuznetsov, N. P. Andreeva, N. P. Sokolova, R. A. Bulgakova and A. M. Gorbunov, Prot. Met., 2007, 43, no. 4, 315.

71. Yu. I. Kuznetsov and N. P. Andreeva, Russ. J. Electrochem., 2010, 46, no. 5, 560.

72. Yu. I. Kuznetsov, M. O. Agafonkina, N. P. Andreeva and A. B. Solov'eva, Prot. Met. Phys. Chem. Surf., 2010, 46, no. 7, 807.

73. Yu. I. Kuznetsov, M. O. Agafonkina, N. P. Andreeva and L. P. Kazansky, Corros. Sci., 2015 (in press). 